\title{
5. Bedeutung und Rechtfertigung
}

In diesem Kapitel werde ich abschließend darlegen, inwiefern die Überzeugungsbedingung für Wissen eine Frage des Könnens ist. Dabei wird sich herausstellen, dass dies ebenso für die Rechtfertigungsbedingung gilt. Ich werde eine inferentielle Semantik ausformulieren mit dem Ziel, „blindes Regelfolgen“ als das Befolgen materialer Inferenzregeln verständlich zu machen. Den Ausgangspunkt bildet die Auffassung, dass sich die Bedeutung eines Ausdrucks aus seinem Gebrauch in der Sprache ergibt. Dies werde ich dahingehend präzisieren, dass ich den Sprachgebrauch auf seine allgemeine Grundlage als Schlussfolgerungspraxis zurückführe. Dadurch wird hervorgehoben, dass Überzeugungen prinzipiell immer in einem inferentiellen Zusammenhang stehen. Das normativ signifikante Sprachspiel der Überzeugung ist stets ein inferentiell gegliedertes. Die Regeln, die dabei implizit befolgt werden, lassen sich daher als Inferenzregeln begreifen. Mit ihrer Hilfe wird die korrekte von der inkorrekten Bedeutung unterscheiden. Der zweite Teil des Kapitels ist einer eingehenden Diskussion des Begriffs der materialen Inferenz sowie der entsprechenden Regeln gewidmet. Ich werde darlegen, weshalb es sich bei materialen Inferenzregeln um eine eigenständige und genuin normative Art von Regel handelt. Anhand von irrealen Bedingungssätzen werde ich zudem zeigen, dass sie formalen Inferenzregeln gegenüber grundlegend sind. Letztlich ist also die Bedeutung von Überzeugungen von derselben Fähigkeit abhängig wie das Rechtfertigen. Beides setzt das Beherrschen von Inferenzregeln voraus. Deswegen ist sowohl das Haben von Überzeugungen als auch das Rechtfertigen eine Form des Könnens.

\subsection{Bedeutung und Sprachgebrauch}

Eine Bedeutungstheorie gibt eine Antwort auf die Frage, wie es kommt, dass die Dinge, die wir sagen, das bedeuten, was sie nun einmal bedeuten. Sie gibt darüber Auskunft, wie sprachliche Äußerungen zu ihren semantischen Eigenschaften kommen. Wer eine solche Auskunft wünscht oder anbietet, geht davon aus, dass Bedeutungen nichts natürlich Gegebenes sind. Dass beispielsweise der Ausdruck „Apfel“ Apfel bedeutet 
und nicht etwa Huhn oder Tasche, ist keine simple Tatsache. Vielmehr ist es so, dass semantischen Eigenschaften von nicht-semantischen Gegebenheiten abhängen und sich durch sie erklären lassen. Man kann auch sagen, dass erstere auf letztere supervenieren. Eine Bedeutungstheorie erfüllt somit die Aufgabe festzustellen, welches diese nicht-semantischen Gegebenheiten sind und nach welchen Prinzipien sie die Bedeutungen sprachlicher Äußerungen bestimmen.

Gemäß einer verbreiteten Auffassung ist Bedeutung darin begründet, dass sprachliche Äußerungen auf eine angemessene Weise in Verbindung zu außersprachlichen Entitäten stehen. Ausdrücke oder Sätze gelten als Beschreibungen oder Repräsentationen von Gegenständen, Sachverhalten, möglichen Welten etc. Die vorrangige Aufgabe einer Bedeutungstheorie ist demzufolge die systematische Erklärung des Umstandes, dass eine sprachliche Äußerung wahr ist, dass sie sich auf Dinge in der Welt bezieht oder dass sie wahrheitsgemäß auf diese angewandt wird. Gemäß dieser Auffassung sind die zentralen, erklärenden Begriffe die der Repräsentation, der Bezugnahme und der Wahrheit. Ansätze, die die semantischen Eigenschaften sprachlicher Ausdrücke mit diesem Fokus bestimmen, kann man als gegenständliche, repräsentationalistische oder wahrheitskonditionale Theorien der Bedeutung bezeichnen.

Die Gebrauchstheorie der Bedeutung ist eine Alternative $\mathrm{zu}$ derartigen Ansätzen. ${ }^{197}$ Bei dieser Herangehensweise ist die Art, wie wir von Sprache Gebrauch machen, maßgeblich für die Bedeutung ihrer Ausdrücke. Nicht die Verbindung zu außersprachliche Entitäten, sondern die Beziehung sprachlicher Äußerungen zueinander im Gebrauch gilt als dasjenige, was Bedeutung konstituiert. Sprache ist hier die ausschließliche Quelle semantischer Eigenschaften. Somit ist die Gebrauchstheorie der Bedeutung die semantische Fortsetzung der normativen Pragmatik. Mit diesem Ansatz bietet sich die Gelegenheit, die Überlegungen zu Regeln und deren Befolgung wieder aufzugreifen. Im Rahmen einer inferentiellen

197 Die Gebrauchstheorie der Bedeutung geht zurück auf Wittgenstein. Vgl. erneut Wittgenstein (1984d), $\S 30,43,80,138$ f., 197, 556 u. 561, Wittgenstein (1984b), 20 u. Wittgenstein (1984f), 61 f. Spätere Vertreter dieser Auffassung sind u. a. W. Sellars, G. Harman, D. Lewis, R. Brandom u. P. Horwich. Vgl. Sellars (1963b), Sellars (1969), Harman (1974), Harman (1987), Lewis (1969), insbes. Kap 5, Lewis (1975), Brandom (1983a), Brandom (1994), insbes. Kap. 1-3, Horwich (1998a) u. Horwich (2005). 
Semantik lässt sich das Verständnis von Regeln präzisieren, welches der Rede von Können als „blindem Regelfolgen“ zugrunde liegt.

Eine Gebrauchstheorie der Bedeutung geht von der allgemeinen Annahme aus, dass jemand die Bedeutung einer sprachlichen Äußerung richtig verstanden hat, wenn er sie richtig zu gebrauchen weiß. Damit wird zunächst nichts weiter getan, als Bedeutung in Abhängigkeit von korrektem Gebrauch zu bringen. In den allermeisten Fällen besteht nun der bedeutungsvolle Sprachgebrauch nicht aus einzelnen Ausdrücken, sondern aus ganzen Sätzen. Wenn wir etwas über die Welt aussagen oder erfragen, dann geschieht das prinzipiell so, dass wir ein logisches Subjekt in Relation zu einem Prädikat setzen. Das heißt, wir bilden Sätze, auch wenn diese gelegentlich aus wenigen oder auch nur einem Wort bestehen. So gesehen sind also nicht Ausdrücke, sondern Sätze die primären Bedeutungsträger. Die Gebrauchstheorie der Bedeutung geht daher von einem Vorrang des Propositionalen aus. Die sprachliche Einheit des Satzes nimmt auch hier eine systematische und explanatorische Sonderstellung ein. ${ }^{198}$ Es gilt die Grundannahme, dass es vorrangig Sätze sind, in denen wir Gedanken oder Überzeugungen äußern oder zuschreiben. Die bedeutsamen Gehalte, die im behauptenden Sprachgebrauch ausgetauscht werden, sind in Sätze eingebunden. Semantischer Gehalt ist somit immer propositionaler Gehalt.

\subsection{Ist die Gebrauchstheorie der Bedeutung eine Petitio principii?}

Gegenüber der Idee, propositionalen oder semantischen Gehalt auf der Grundlage einer normativen Pragmatik zu erklären, wird gelegentlich der Verdacht geäußert, dabei werde zirkulär argumentiert. ${ }^{199}$ Indem er den Sprachgebrauch zum Explanans für das Explanandum von Gehalt und Bedeutung mache, setze dieser Erklärungsansatz voraus, was er eigentlich erklären möchte. Schließlich verstehe er den Sprachgebrauch als sprachliches Handeln, welches nur als eine Form des intentionalen Handelns begriffen werden könne. Eine Absicht sei also ein fundamentaler Bestandteil einer jeden Handlung. Hierbei handle es sich aber

\footnotetext{
${ }^{198} \mathrm{Vgl}$. auch erneut Kap. 4.3.

199 Vgl. Davidson (1984), 271, Boghossian (1989), 517, Glüer (1999b), 38 f., Tietz (2003), 75 ff. o. Lauer (2009), 326 f. u. 335.
} 
offensichtlich um eine propositionale Einstellung, die selbst wiederum auf propositionalen Gehalt zurückgreife. Sprachliches Handeln, verstanden als intentionales Handeln, setze demnach immer schon den Begriff des propositionalen Gehalts voraus. Es könne also nur um den Preis einer Petitio principii zur Erklärung oder Begründung von propositionalem oder semantischem Gehalt verwendet werden.

Dazu ist zunächst zu sagen, dass der ursprüngliche Erklärungsansatz, den ich in Anlehnung an Brandom und Sellars vertrete, über jeden Zirkularitätsverdacht erhaben ist. Denn es kommt darin kein intentionales oder semantisches Vokabular vor, wenn es um die Erklärung von Bedeutung geht. Der geschilderte Verdacht kann erst dadurch entstehen, dass ihm dieses Vokabular nachträglich hinzugefügt wird mit der Begründung, darauf könne aus begrifflicher Notwendigkeit nicht verzichtet werden. Der Begriff der Handlung impliziere notwendig den der Absicht und damit den des intentionalen, propositionalen und semantischen Gehaltes. Die Frage ist also, ob es möglich ist, über diskursive Praktiken zu reden, ohne auf den Begriff der Absicht zurückzugreifen.

In der normativen Pragmatik geht es um eine Rekonstruktion des Meinens oder Habens von Überzeugungen in rein normativen Begriffen. Die sprachliche Praxis gilt sowohl in systematischer als auch in explanatorischer Hinsicht als der vorrangige Ort, wo Überzeugungen vorkommen. Ihre primäre Erscheinungsform sind Behauptungen, die zunächst einer rein normativ verfassten Welt angehören. Als solche verfügen sie über eine normative Kraft, die durch die implizit normative, soziale Praxis instituiert wird. Maßgeblich dafür ist das wechselseitige positive und negative Sanktionieren der Diskursteilnehmer. Auf der elementarsten Betrachtungsebene ist die diskursive Praxis also eine durchgängig normative Angelegenheit. Die Teilnehmer weisen sich im Rahmen von komplexen normativen Strukturen wechselseitig Beurteilungen zu. Dabei sind diese Spielzüge ursprünglich nichts weiter als rudimentäre sprachliche Performanzen. Ich habe sie mit Brandom als Festlegungen, Berechtigungen und Unvereinbarkeiten kategorisiert.

Propositionalen und semantischen Gehalt gibt es hier nur in einem relationalen und abgeleiteten Sinne. Auf der Grundlage des koordinierten Zusammenspiels normativer Elemente kommt es zu der Übertragung von Gehalten. Indem Sprecher Festlegungen und Berechtigungen eingehen und 
zuschreiben, etablieren sie inferentielle Zusammenhänge zwischen den sprachlichen Performanzen. So bekommt das Gesprochene tatsächlich semantischen Gehalt. Zu der Rückbindung einer inferentiellen Semantik an eine normative Pragmatik wird im Folgenden noch einiges zu sagen sein. Jedenfalls können Sprecher mit dem Gesagten nur deshalb etwas anfangen, weil sie sich in normativer Hinsicht in der diskursiven Praxis engagieren. Nur deshalb ist die diskursive Praxis letztlich auch ein System sinnvoller und verständlicher Sprechhandlungen. Ohne den normativen Subtext ist semantischer Gehalt nicht möglich. So gesehen ist die diskursive Praxis letztlich durchaus semantisch gehaltvoll, nicht aber die singuläre Sprechhandlung.

Richtig ist also, dass die diskursive Praxis aus intentionalen Handlungen besteht. Wenn jemand eine Behauptung macht, dann ist das kein Ereignis, dass ihm widerfährt. Es ist etwas, das er absichtlich tut. Falsch ist hingegen anzunehmen, dass dabei eine von der sprachlichen Performanz losgelöste und eigenständige Absicht ins Bewusstsein des Sprechers oder sonst irgendwie in Erscheinung treten muss. Die Sprechhandlung erfolgt nicht, nachdem zuvor eine Absicht ausgebildet wurde. Handlung und Absicht bilden eine untrennbare Einheit. Diesem Umstand trägt Searle Rechnung, wenn er die Unterscheidung zwischen „Handlungsabsicht“ und ,vorausgehender Absicht“ einführt. ${ }^{200}$ Im Fall von vorausgehenden Absichten sagen wir auch, dass ein Handelnder nach seiner Absicht handelt oder dass er seine Absicht ausführt. Bei Handlungsabsichten sagen wir dagegen lediglich, dass jemand eine Handlung vollzieht oder einfach dass er handelt. Die Handlungsabsicht ist kein selbständiger Bestandteil der Handlung, sondern kommt darin nur gebunden vor. Und das gilt nun insbesondere für die Sprechhandlung des Behauptens.

Das Behaupten als die grundlegendste Performanz der diskursiven Praxis ist kein intentionales Handeln mit einer vorausgehenden Absicht. In der einzelnen Behauptung für sich genommen kommt die Absicht lediglich in Form einer Handlungsabsicht vor. Man kann auch sagen, dass sie darin implizit enthalten ist. ${ }^{201}$ Ein Sprecher bildet nicht zuerst die Absicht aus,

\footnotetext{
${ }^{200}$ Vgl. Searle (1983), $84 \mathrm{f}$.

${ }^{201}$ Vgl. Brandom (1994), 670 Anm. 6.
} 
sich mit einer Behauptung auf einen bestimmten Gehalt festzulegen, um sie dann durch seine Behauptung zu erfüllen. Er macht sie einfach. Erst als Teil der diskursiven Praxis ist die Absicht ein individuierbarer und thematisierbarer Bestandteil der Sprechhandlung. Rückblickend, beispielsweise in Reaktion auf eine Nachfrage, kann der Sprecher angeben, was die Absicht seiner Behauptung war. Dann kann auch überprüft werden, ob sie sich mit seinem Handeln deckt. Allerdings ist dies dann eher eine Absicht, die über die fragliche Behauptung hinausweist, etwa weil sie darauf abzielt, zu belehren, zu beeindrucken, zu unterhalten, zu überreden, $\mathrm{zu}$ warnen etc. ${ }^{202}$ Zuvor jedoch ist sie ein immanenter Bestandteil der Behauptung. Erst der Umstand, dass die diskursive Praxis normativ verfasst und inferentiell gegliedert ist, macht es, dass intentionale oder propositionale Gehalte semantische Gehalte sein können.

In den folgenden Abschnitten werde ich einige wichtige Gründe dafür liefern, dass Sätze die primären Bedeutungsträger sind. Ich werde darlegen, warum eine Sprachkonzeption, nach der zunächst jedem einzelnen Ausdruck eine individuelle Bedeutung zukommt, inkohärent ist. Als Alternative dazu werde ich den Gedanken weiterentwickeln, dass die Bedeutung sprachlicher Äußerungen an den Sprachgebrauch gebunden ist. Entscheidend ist hierbei die Einsicht, dass es nicht ausreicht, allein die Bedingungen oder Umstände einer Äußerung zu berücksichtigen. Zur Bestimmung von Bedeutung sind deren Konsequenzen oder Folgen ebenso wichtig. Bedeutung begreife ich daher als etwas, das sich aus inferentiellen Zusammenhängen ergibt. Die Gebrauchstheorie der Bedeutung ist letztlich eine inferentielle Semantik. ${ }^{203}$

\subsection{Umstände der Verwendung}

Beginnen wir mit einer einfachen und einleuchtenden Feststellung: Wer einen Ausdruck richtig zu gebrauchen weiß, kennt die Bedingungen, unter denen es gerechtfertigt ist, eine entsprechende Aussage zu machen. Er kennt die Umstände, unter denen es angemessen ist, einen bestimmten Ausdruck in einer Aussage zu verwenden. Man könnte annehmen, dass

\footnotetext{
${ }^{202}$ Davidson nennt dies einen ,weiterreichenden Zweck“. Vgl. Davidson (1984), 272. ${ }^{203}$ Vgl. v. a. Sellars (1953), Sellars (1963a), Sellars (1963b), Dummett (1973), 453 f. u. Brandom (1994), insbes. Kap. 2 u. 3.
} 
diese Bedingung im Prinzip immer dann erfüllt ist, wenn ein Gegenstand oder Sachverhalt der betreffenden Art in der Umgebung vorhanden ist. ${ }^{204}$ Für den paradigmatischen Fall von Aussagen über Gegenstände der Wahrnehmung ist dies eine naheliegende Überlegung. Dass beispielsweise ein Apfel unter normalen Bedingungen in der Umgebung vorhanden ist, lässt sich als ein angemessener Umstand für die Verwendung des Ausdrucks „Apfel“ begreifen. Wieso sollte dies nicht ausreichen, um tatsächlich auch die Bedeutung einer entsprechenden Aussage zu bestimmen?

Nehmen wir an, die Bedeutungen sprachlicher Äußerungen wären allein durch die Umstände ihrer Verwendung bestimmt. Nach diesem Verständnis würden einzelne Wörter Gegenstände benennen und Sätze die Verbindungen solcher Benennungen darstellen. ${ }^{205}$ Als primäre Bedeutungsträger gälten also nicht Sätze, sondern einzelne Ausdrücke. Einen solchen Ansatz kann man als atomistisch bezeichnen. Ihm zufolge kommt sprachlichen Ausdrücken ihre Bedeutung dadurch zu, dass sie durch Hinweise definiert werden. Der Ausdruck „Apfel“ etwa bedeutet Apfel, weil diese Bedeutung durch den Hinweis auf einen Apfel in der Nähe eingeführt wurde. Das Prinzip also, wonach sich die Bedeutung eines sprachlichen Ausdrucks bestimmt, ist die abgrenzende Festlegung durch einen Hinweis auf einen Gegenstand oder Sachverhalt. Ihm wird eine mentale Entität zugeordnet und durch einen entsprechenden Ausdruck dargestellt.

Wieso ist ein solcher Erklärungsansatz unzutreffend? Der Grund dafür ist, dass hinweisende Definitionen zu ungenau und unvollständig sind, um Bedeutungen unzweideutig angeben zu können. Denn wenn jemand auf etwas zeigt und dabei „Apfel“ sagt, ist noch lange nicht klar, was genau der Ausdruck in der Umgebung des Sprechers herausgreift. Ist es eine Farbe, eine Form, ein bestimmtes Gewicht oder die Zugehörigkeit zu einer bestimmten Sorte von Gegenständen? Hinweisende Definitionen geben

204 „Im Prinzip“ deswegen, weil ein solcher Gegenstand oder Sachverhalt natürlich nicht immer vorhanden sein muss. Es genügt, wenn er bei Bedarf vorgewiesen oder rekonstruiert werden kann.

${ }^{205}$ Vgl. insbes. auch zum Folgenden Wittgenstein (1984d), §§ 1 ff. u. 28 ff. Vgl. auch erneut Kap. 3.3. 
hier keine befriedigende Antwort. Wer über eine solche Definition verfügt, verfügt noch lange nicht über die Bedeutung des fraglichen Ausdrucks. ${ }^{206}$

Ein ähnliches Problem ergibt sich, wenn wir Bedeutung durch kausale Relationen $\mathrm{zu}$ erklären versuchen. ${ }^{207}$ Die Idee ist dabei die, dass ein bestimmtes Vorkommnis oder ein bestimmter Sachverhalt kausal für die Bedeutung eines Ausdrucks verantwortlich ist. Das Problem, das sich aus diesem Erklärungsmodell ergibt, ist als Disjunktionsproblem bekannt. ${ }^{208}$ Es taucht genau dann auf, wenn bestimmte Ausdrücke auf verschiedene Vorkommnisse angewendet werden oder wenn verschiedene Vorkommnisse bei einem Sprecher denselben Ausdruck hervorrufen. Im Kern besteht das Problem also darin, dass prinzipiell mehr als ein Vorkommnis kausal in bedeutungsbestimmender Relation $\mathrm{zu}$ einem sprachlichen Ausdruck stehen kann.

Paradigmatisch hierfür sind Fehler oder Irrtümer. Wird ein Vorkommnis oder Sachverhalt irrtümlicherweise für etwas anderes gehalten, als was sonst mit ihm in Zusammenhang gebracht wird, so kommt es zu einer solchen mehrdeutigen oder instabilen Relation. Nehmen wir beispielsweise den Ausdruck „Eichhörnchen“. In einer dunklen und nebligen Nacht im Park befindet sich in einiger Entfernung von mir ein Hase. Ich halte aber das, was ich sehe, für ein Eichhörnchen. Also verwende ich zur Bezeichnung dieses Vorkommnisses den Ausdruck „Eichhörnchen“. Mag mir damit auch ein Fehler unterlaufen, so hat der Ausdruck, so wie ich ihn verwende, dennoch die Bedeutung Eichhörnchen. Offensichtlich sind es also nicht nur Vorkommnisse der Art Eichhörnchen, sondern auch solche der Art Hase, die in mir den Ausdruck „Eichhörnchen“" hervorrufen.

Aber nicht nur Irrtümer sind mögliche Ursachen für Ausdrücke und ihre Bedeutung. Auch wahre Gedanken oder Impulse, die nicht von Eichhörnchen, sondern von Erinnerungen, freien Assoziationen, ironischen Bemerkungen etc. verursacht werden, können sie hervorrufen. Erzählt mir

206 Vgl. auch Quine (1960), insbes. 51 ff., wo es um die Schwierigkeit geht, die Bedeutung von „Kaninchen“, „Zeitsegment eines Kaninchens“, „,zusammenhängendes Kaninchenteil" etc. zu unterscheiden.

${ }^{207}$ Vgl. z. B. Field (1972), Fodor (1987), insbes. Kap. 4, Fodor (1990), insbes. Kap. 4 u. Dretske (1997).

${ }^{208}$ Vgl. z. B. Godfrey-Smith (1989) u. Fodor (1984). 
jemand beispielsweise von seinem Spaziergang im Park, so kann dies bei mir den Ausdruck „Eichhörnchen“ hervorrufen, ohne dass in diesem Moment ein solches in der Nähe ist oder in irgendeinem anders gearteten kausalen Verhältnis zu dem Ausdruck steht. Eine kausale Theorie der Bedeutung kann jedoch nicht erklären, wieso beispielsweise der Bericht von einem Spaziergang im Park in mir den Ausdruck „Eichhörnchen“ hervorruft. Man mag der Theorie mehr zugestehen, als dass sie jedem Ausdruck nur genau ein Vorkommnis zuweist. Sie müsste allerdings angeben können, wie die semantisch relevante unter all den möglichen Kausalrelationen herausgegriffen wird. Dazu aber sind Wort-VorkommnisRelationen viel zu variabel.

Das gemeinsame Problem derartiger atomistischer und repräsentationalistischer Bedeutungstheorien liegt im Unterschied von Referenz und Bedeutung sprachlicher Ausdrücke. ${ }^{209}$ Unterschiedliche Ausdrücke können sich auf ein und dasselbe Vorkommnis in der Welt beziehen, dabei aber unterschiedliche Bedeutungen haben. Freges bekanntes Beispiel hierfür sind die Ausdrücke „Morgenstern“ und „Abendstern“. Beide beziehen sich auf dasselbe nichtsprachliche Vorkommnis, haben allerdings nicht dieselbe Bedeutung. Umgekehrt ist es möglich, dass sich unterschiedliche Wort-Vorkommnis-Relationen dieselbe Bedeutung teilen. Der Ausdruck „Eichhörnchen“ beispielsweise steht dann sowohl zu Eichhörnchen als auch zu Hasen oder Spaziergängen im Park in Beziehung.

Eine Bedeutungstheorie, die den Sprachgebrauch ins Zentrum seiner Überlegungen rückt, wird mit dieser Problematik nicht konfrontiert. Ihr Interesse gilt nicht einer metaphysischen oder formalen Relation zwischen sprachlichen Phänomenen, mentalen Repräsentationen und Vorkommnissen in der Welt. Vielmehr ist sie darauf gerichtet, was wir tun, wenn wir Wörter oder Zeichen in unterschiedlichen Zusammenhängen gleichbleibend verwenden. Dies besteht zunächst einmal darin, dass wir Ausdrücke in Satzzusammenhänge bringen. Daher kann man die Gebrauchstheorie als eine molekulare Theorie der Bedeutung

${ }^{209}$ Vgl. hierzu auch erneut Anm. 10. Zu den wahrheitstheoretischen Aspekte dieses Problems vgl. auch Kap. 6.3. 
bezeichnen. ${ }^{210}$ Allerdings stellen sich die erwähnten Probleme auch dann, wenn Ausdrücke in Satzzusammenhängen stehen. Denn auch dann ist die Bedeutung problematisch, sofern sie nur durch die angemessenen Umstände der Verwendung bestimmt wird. Wie ich im Folgenden zeigen werde, ist die Gebrauchstheorie dennoch die bessere Alternative.

\subsection{Folgen der Verwendung}

Dass die angemessenen Umstände der Verwendung einer sprachlichen Äußerung genügend Hinweise auf ihre Bedeutung geben, hat sich als eine Fehleinschätzung herausgestellt. Denn sie allein informieren nicht darüber, wozu genau die Äußerung in Beziehung steht. Man kann zwar versuchen, durch eine präzisere Eingrenzung des Gegenstandsbereichs Abhilfe zu schaffen. Letztlich gilt aber selbst für einen so aufschlussreichen Satz wie „Der runde, rote Gegenstand, der dort drüben unter dem Baum im Gras liegt und sich beim Aufheben glatt anfühlt, wird als ,Apfel' bezeichnet.“, dass er allein nicht zur Bestimmung der Bedeutung des Ausdrucks „Apfel“ dienen kann. Das gilt selbst dann, wenn sich in der Umgebung unter den beschriebenen Umständen ein Apfel befindet. Warum ist das so?

Um dies zu erklären, muss man sich ein weiteres Problem für gegenständliche Bedeutungstheorien bewusst machen. Ich will es das Thermometerproblem nennen. ${ }^{211}$ Es spielt dabei keine Rolle, ob die Theorie atomistisch oder molekular aufgefasst wird, ob also einzelne Ausdrücke oder ganze Sätze die primären Bedeutungsträger sind. Angenommen es gibt einen Detektor, der so konstruiert ist, dass er genau dann ein Signal von sich gibt, wenn er einem Apfel ausgesetzt wird. Dieses Signal besteht beispielsweise in der zuverlässigen Wiedergabe des Satzes:

\footnotetext{
${ }^{210}$ Wie subsententiale Einheiten wie singuläre Termini oder Prädikate zur Bedeutung von Aussagen beitragen, erklärt z. B. Brandom mit Hilfe der Begriffe der Substitution und der Anapher. Vgl. Brandom (1994), Kap. 6, insbes. 360 ff. u. Kap. 7, insbes. 449 ff. Für eine kompakte Darstellung vgl. Esfeld (2002), 81 ff.

${ }^{211}$ Dieser Ausdruck geht auf W. Sellars und H. H. Price zurück. Vgl. Sellars (1963a), 162 u. 167. Das folgende Beispiel verdanke ich Brandom. Vgl. Brandom (1994), 87 ff. u. 122. Vgl. aber auch Putnam (1981), 18 ff., Bieri (1982), 5 u. Sellars (1963a), 162 f.
} 
„Dies ist ein Apfel.“212 Man könnte also sagen, dass der Detektor unter den angemessenen Umständen von dem Ausdruck „Apfel“" Gebrauch macht. Ein ganz ähnliches Szenario wäre es, wenn ein Papagei darauf abgerichtet wäre, denselben Satz unter genau denselben Umständen von sich zu geben. Kennt nun der Detektor oder der Papagei die Bedeutung des Ausdrucks „Apfel“? Wer dies bejaht, muss ebenso behaupten, dass ein Thermometer mit der Bedeutung von Ausdrücken wie „minus zwei Grad Celsius“ oder „zweiunddreißig Grad Fahrenheit“" vertraut ist. Aber wer würde das allen Ernstes tun?

Der Punkt ist dabei nicht, dass es sich in diesen Beispielen um Tiere oder Maschinen handelt. Wir würden auch bei einer Person daran zweifeln, dass sie die Bedeutung eines Ausdrucks wie beispielsweise „Diatomeenfilter“ kennt, wenn sie damit immer nur auf bestimmte Umstände mit der Behauptung „Dies ist ein Diatomeenfilter.“ reagiert. Das Problem ist vielmehr, dass wir weder von dem Apfel-Detektor noch von dem Papagei bereit wären zu sagen, dass sie begriffen oder verstanden haben, was ein Apfel ist, wenn sie den Satz „Dies ist ein Apfel.“ äußern. Alles, was sie tun, ist, verlässlich unterscheidend auf ihre Umwelt zu reagieren. Nichts anderes tut ein Thermometer, wenn es beispielsweise minus zwei Grad Celsius anzeigt. Was also fehlt in all diesen Fällen?

Wer tatsächlich verstanden hat, was eine Aussage wie „Dies ist ein Apfel.“ oder „Dies ist ein Diatomeenfilter.“ bedeutet, kann mehr, als die entsprechenden Umstände verlässlich zu erkennen oder zu unterscheiden. Wer von solchen Sätzen auf bedeutsame Weise Gebrauch machen will, kann mit ihnen auch etwas anfangen. Er weiß nicht nur, was die Bedingung dafür ist, damit etwas als „Diatomeenfilter“ oder als „Apfel“ bezeichnet werden kann. Er weiß auch, welche Konsequenzen dies hat. Er kann einschätzen, welches die angemessenen Folgen der Verwendung dieser Ausdrücke in entsprechenden Aussagen sind. Dies ist es, was fehlt, wenn jemand oder etwas lediglich unter den angemessenen Umständen mit einer bestimmten Aussage reagiert.

${ }^{212}$ Sicher ließe sich der Detektor auch so konstruieren, dass er in der fraglichen Situation einen wesentlich komplexeren Satz von sich gibt. Für die Problematik, um die es mir geht, ist ein einfaches Beispiel jedoch ausreichend. 
Das zuverlässige Reagieren auf gewisse Umstände mit einer einzigen, ganz bestimmten Aussage oder Behauptung hat nichts mit dem tatsächlich bedeutungsvollen Gebrauch zu tun. So wenig man die Bedeutung eines einzelnen Ausdrucks kennen kann, so wenig kann man die eines einzigen Satzes kennen. Ebenso verkehrt wäre die Vorstellung, jemand könnte die Bedeutung einzelner oder isolierter Sätze kennen. Wer beispielsweise die Sätze „Dies ist ein Apfel.“ und „Dies ist ein Diatomeenfilter.“ völlig abgesondert von anderen Sätzen kennt, für den können sie keine Bedeutung haben. Eine Grundvoraussetzung für das Verständnis eines Ausdrucks ist vielmehr die Kenntnis eines „Spielraums von sinnvollen Sätzen“, in denen er auftreten kann. ${ }^{213}$ Zum Gebrauch eines Ausdrucks gehört ein gewisses $\mathrm{Ma} 3$ an Flexibilität, was seinen Einsatz im Satzzusammenhang angeht. Die Rede von Bedeutung ist erst sinnvoll, wenn man eine Auswahl an Sätzen kennt, die einen paradigmatischen Gebrauch eines bestimmten Ausdrucks darstellen.

Der Umfang einer solchen Auswahl kann innerhalb einer sprachlichen Gemeinschaft stark variieren. Das Verständnis der Bedeutung von Aussagen ist eine graduelle Angelegenheit. Schließlich verfügt jedes Mitglied über ein anderes Repertoire an bedeutsamen Sätzen. So hat etwa ein Obstbauer ein umfassenderes Verständnis von dem Ausdruck „Apfel“ als ein Kind. ${ }^{214}$ Damit das Kind aber überhaupt die Bedeutung von Aussagen verstehen kann, in denen der Ausdruck vorkommt, muss es eine repräsentative Auswahl an Aussagen kennen, in denen auf paradigmatische Weise von ihm Gebrauch gemacht wird. Diese Auswahl variiert wiederum mit der Komplexität des jeweiligen Ausdrucks. Der Ausdruck „Apfel“ beispielsweise bedarf, um verstanden zu werden, einer anderen, weniger umfassenden Auswahl an Sätzen, als der Ausdruck „Gravitationsfeld“.

${ }^{213}$ Vgl. Bieri (1982), 4.

${ }^{214}$ Dass aber zwei Personen mit demselben Ausdruck nicht zwei vollkommen unterschiedliche Bedeutungen in Verbindung bringen, erklärt sich aus der sozialen Dimension der Bedeutungskonstitution. Bedeutung resultiert niemals nur aus den angemessenen Umständen und Folgen des Gebrauchs einer einzigen Person. Sie ist immer an den Gebrauch in einer sprachlichen Gemeinschaft gebunden. Dies ist auch eine Erklärung dafür, dass sich die Bedeutungen für eine Person nicht permanent ändern, sobald sich sein Repertoire bedeutsamer Sätze ändert. Zu einer ausführliche Diskussion dieser Thematik vgl. Esfeld (2002), 72 ff. u. 93 ff. u. Williams (2004), 110 ff. 
Eine Konsequenz der These, dass die Bedeutung eines Ausdrucks den Überblick über die Umstände und Folgen seiner Verwendung in einer entsprechenden Aussage voraussetzt, ist somit die eines semantischen Holismus, der immer auch ein sozialer Holismus ist. ${ }^{215}$ Demnach muss man, um überhaupt einen Satz mit semantischem Gehalt verwenden zu können, viele Sätze kennen und mit Teilen oder der Gesamtheit einer sprachlichen Gemeinschaft teilen. Weil Bedeutung eine determinierbare, generische und soziale Eigenschaft ist, hat etwas nicht einfach Bedeutung, sondern es hat eine spezifische Bedeutung. Und es kann nur dann eine spezifische Bedeutung haben, wenn es etwas anderes von derselben Art gibt, das ebenfalls diese Eigenschaft hat. Wenn also ein Satz Bedeutung oder semantischen Gehalt hat, dann muss es andere Sätze geben, die es ebenfalls haben und innerhalb einer sprachlichen Gemeinschaft Verwendung finden.

Was seine Bedeutung angeht, so kann ein Satz nicht isoliert betrachtet werden. Einem Satz kommt nur insofern ein semantischer Gehalt zu, als es ein ganzes System von Sätzen mit dieser Eigenschaft gibt. ${ }^{216}$ Somit ist die Bedeutung eines Satzes von der Bedeutung anderer Sätze ontologisch abhängig. Jeder Satz, der eine Bedeutung hat, ist abhängig davon, dass es irgendeinen anderen Satz gibt, der eine andere Bedeutung hat. Insofern lässt sich die Bedeutung einer sprachlichen Äußerung nicht mittels verlässlich unterscheidender Reaktionen auf nichtsprachliche Reize erklären. Eine Sprache, in der von Ausdrücken oder Sätzen ausschließlich reagierend und berichtend Gebrauch gemacht wird, ist eine Sprache ohne Bedeutung. Auch für Berichte von Wahrnehmungen oder mentalen Ereignissen ist entscheidend, dass sie mit anderen Aussagen in einem funktionalen Zusammenhang stehen. Erst dadurch erhalten sie ihre jeweilige Bedeutung.

\subsection{Sprachliche Umstände und Folgen}

Die bisherigen Beispiele zur Veranschaulichung des bedeutsamen Gebrauchs von Sätzen oder Aussagen umfassten deren empirisch oder

${ }^{215}$ Vgl. Esfeld (2002), insbes. 32, $41 \mathrm{ff} ., 52 \mathrm{ff}$.

${ }^{216} \mathrm{Zu}$ der Position, wonach sich der semantische Gehalt eines Systems von Sätzen aus dem seiner Konstituenten ableitet, vgl. ebd., 41 ff. u. 62 ff. 
perzeptiv gegebenen Umstände auf der einen Seite sowie deren sprachlichlogischen Folgen auf der anderen. Die diskursive Situation besteht aber nicht selten aus rein sprachlichen Zusammenhängen. In der Regel sind nicht nur sprachliche Folgen, sondern auch sprachliche Umstände an der Konstitution von Bedeutung beteiligt. Die Umstände einer Aussage sind dann wiederum Aussagen, die aber keineswegs nur auf empirische Gegebenheiten Bezug nehmen. Für eine solche rein sprachliche Form der Bedeutungskonstitution stellt sich aber die Frage, ob tatsächlich die Umstände und Folgen Berücksichtigung finden müssen. Das Thermometerproblem hat zwar gezeigt, dass sich Bedeutung nicht ausschließlich durch die Kenntnis der perzeptiven Umstände bestimmen lässt. Lässt sich dies aber verallgemeinern? Sind bei der innersprachlichen Bedeutungskonstitution ebenfalls beide Seiten entscheidend, also das, woraus etwas folgt, und das, was folgt?

Für eine positive Antwort auf diese Frage spricht die Tatsache, dass es bedeutsame Aussagen gibt, die unter denselben Umständen unterschiedliche Folgen der Verwendung haben können. Dies lässt sich mit Hilfe von pragmatisch explizierenden Redewendungen veranschaulichen. Dabei handelt es sich um Redewendungen, die es ermöglichen, ausdrücklich zu sagen, was man tun wird. ${ }^{217}$ Betrachten wir beispielsweise die folgenden beiden Aussagen:

(8) Ich werde Johanna heiraten.

(9) Ich sehe voraus, dass ich Johanna heiraten werde.

Bei (9) handelt es sich um eine solche pragmatisch explizierende Redewendung. Das Subjekt des Satzes kündigt an, etwas zu tun, und bringt dies im Sprechakt selbst zum Ausdruck. Dagegen beinhaltet (8) nur das, was getan werden soll, ohne dies zugleich ausdrücklich zu sagen.

Die Umstände, unter denen (8) angemessen ist, sind dieselben, unter denen auch (9) angemessen ist. Dazu gehören generelle Voraussetzungen wie beispielsweise „Johanna und ich sind unverheiratet.“ oder „Johanna

${ }^{217}$ Vgl. Brandom (1994), 121 f. Vgl. insbes. zu den folgenden Beispielen auch Brandom (1976). 
hat das 16. Lebensjahr vollendet.““218 Aber auch konkretere Umstände wie „Johanna hat versprochen, mich zu heiraten.“ oder „Ich habe eine schriftliche Bestätigung für den Termin unserer Trauung." erlauben den Schluss sowohl auf (8) als auch auf (9). Immer, wenn die Umstände es angemessen erscheinen lassen, dass ich Johanna heiraten werde, ist es auch angemessen, dass ich dies vorhersehe. Mit den Folgen, die diese beiden Aussagen angemessenerweise haben können, verhält es sich jedoch anders. Sie sind durchaus verschieden. Während etwa aus „Ich werde Johanna heiraten.“ trivialerweise folgt „Ich werde Johanna heiraten.“, gilt dies für „Ich sehe voraus, dass ich Johanna heiraten werde." nicht. Dazu müsste zusätzlich geklärt werden, wie gut ich darin bin, Dinge oder Ereignisse vorauszusagen.

Dieser Unterschied lässt sich zusätzlich verdeutlichen, indem man die Verwendung von Aussagen dieser Art als Antezedenzien in Konditionalen betrachtet. Dann nämlich zeigt sich, dass zwar (8) und (9) unter denselben Umständen angemessen sind, nicht aber die mit ihnen gebildeten Konditionale. Die variierende Gültigkeit der Konditionale auf der Umstandsseite ist eine Konsequenz der Variabilität ihrer Antezedenzien auf der Folgenseite. Betrachten wir die folgenden beiden Konditionale:

(10) Wenn ich Johanna heiraten werde, werde ich Johanna heiraten.

(11) Wenn ich voraussehe, dass ich Johanna heiraten werde, werde ich Johanna heiraten.

Die Umstände, unter denen es gerechtfertigt ist, sie zu verwenden, sind recht unterschiedlich. Das Konditional in (11) kann nur unter der zusätzlichen Voraussetzung verwendet werden, dass meine Voraussage richtig ist. Dann folgt das Konsequenz tatsächlich aus dem Antezedens. Für das Konditional in (10) ist dies völlig unbedeutend. Hier folgt das Konsequenz immer aus dem Antezedens.

Es ist also die folgende Situation entstanden. Die Verwendung zweier Aussagen für sich betrachtet ist unter denselben Umständen angemessen. Werden sie dagegen als Antezedenzien eines Konditionals mit demselben

218 Nach BGB § 1303 Abs. 2 ist auf Antrag ehefähig, wer mindestens das 16. Lebensjahr vollendet hat, sofern der künftige Ehepartner volljährig ist. Vgl. Köhler (2001), 249. 
Konsequenz verwendet, unterscheiden sich die Umstände ihrer angemessenen Verwendung. Der Grund dafür ist, dass für die beiden Antezedenzien nicht dasselbe Konsequenz eine angemessene Folge darstellt. Für eine Semantik, die allein die Umstände der Verwendung von Aussagen berücksichtigt, ist dies ein Problem. Sie kann nicht erklären, warum sich durch das Ersetzen des Antezedens durch einen vermeintlich bedeutungsgleichen Satz ein Konditional ergeben kann, dessen Bedeutung nicht mehr dieselbe ist. Es zeigt sich also, dass die Umstände allein auch in rein innersprachlichen Zusammenhängen nicht zur Bestimmung von Bedeutung ausreichen. Nicht nur, wenn es um Wahrnehmungsberichte geht, sind die Folgen der Verwendung entscheidend. Auch Aussagen, die sich auf andere Aussagen stützen, sind erst dann semantisch eindeutig identifizierbar, wenn zugleich bekannt ist, welche Aussagen sie selbst stützen.

Die Folgen einer Aussage sind zumeist weitere Aussagen, die mit dieser auf relevante Weise zusammenhängen. Anstatt von den Folgen einer Aussage kann man auch von den Inferenzen reden, die mit ihr in Zusammenhang stehen. Die Kenntnis der Bedeutung eines Ausdrucks ist dann gleichbedeutend mit dem Überblick über den inferentiellen Zusammenhang der Aussage, in der dieser vorkommt. Das meint auch Sellars berühmte Rede vom „logischen Raum der Gründe.“219 Ein Ausdruck ist nur dann bedeutsam, wenn er in diesem Raum der inferentiellen Zusammenhänge platziert wird. Anders gesagt beherrscht jemand den bedeutungsvollen Gebrauch eines sprachlichen Ausdrucks nur dann, wenn er es versteht, ihn als Grund zu verwenden.

Das Beherrschen inferentieller Zusammenhänge ist ein elementarer Bestandteil eines jeden kompetenten und damit bedeutsamen Umgangs mit Sprache. Die sprachliche Praxis in ihrer Grundform der aufrichtigen und direkten behauptenden Rede ist davon geprägt, dass Geltungsansprüche problematisiert werden. ${ }^{220}$ Als Diskursteilnehmer sind wir stets angehalten, diese Ansprüche zu bekräftigen oder ihre Bekräftigung einzufordern. Um eine Aussage zu stützen, machen wir weitere Aussagen, so wie wir dies

${ }^{219}$ Vgl. Sellars (1963a), 169. Vgl. auch Davidson (1984), 225. Davidson setzt die Bedeutung eines Satzes mit seinem ,semantischen Ort“ in der Sprache gleich.

${ }^{220} \mathrm{Zu}$ einer Erörterung dieses Themas unter dem Titel „Practical Mode of Belief“" vgl. auch Pettit (1998), insbes. 20 ff. 
auch von anderen Diskursteilnehmern einfordern. Möglich wird dies, weil Aussagen prinzipiell in einem relevanten und unmittelbaren Zusammenhang mit anderen Aussagen stehen. Grundsätzlich kann jeder Aussage eine weitere auf sinnvolle und relevante Weise angeschlossen werden. Mit einem Wort, jeglicher Diskurs ist prinzipiell inferentiell gegliedert.

Hier nun überschneiden sich die Beschreibungsebenen. Denn was auf pragmatischer Ebene die implizite Normativität ist, ist auf semantischer Ebene die inferentielle Gliederung. Dass bedeutsame Sprache inferentiell gegliedert ist, entspricht der Einsicht, dass Sprecher sich auf rationale Standards verpflichten, wenn sie Behauptungen machen. Damit tritt auch die doppelte Relevanz des Propositionalen für die anvisierte Bedeutungstheorie in den Blick. Denn indem sie explanatorisch dort ansetzt, wo Bedeutung auch vortheoretisch vorrangig auftaucht, nämlich im Sprachgebrauch, steigt sie auf der Satzebene ein. Und indem sie auf der Satzebene einsteigt, wird die Erklärung von Bedeutung auf der Grundlage inferentieller Zusammenhänge möglich. Schließlich stehen nicht Ausdrücke, sondern Sätze derart in Zusammenhang.

Inferentielle Zusammenhänge sind Begründungszusammenhänge. Gründe jedoch kommen nur in Form von Überzeugungen vor. Etwas kann nur dann als Grund für eine Überzeugung gelten, wenn es selbst eine Überzeugung ist. ${ }^{221}$ Das pragmatische Pendant von Überzeugungen sind satzförmige Aussagen oder Behauptungen. Soll also ein sprachlicher Ausdruck als Grund verwendet werden, so muss er Teil einer solchen Aussage sein. Insofern Inferenzen also bedeutungsbestimmend sind, sind Sätze oder Aussagen die primären Bedeutungsträger. Damit zeichnet sich zugleich ab, dass auf der Ebene der Bedeutungskonstitution bereits das angelegt ist, was auf einer übergeordneten Ebene zur Standardanalyse von Wissen gehört. Danach erwarten wir von jemandem, der etwas zu wissen vorgibt, dass er die entsprechende Überzeugung auch rechtfertigen kann. Nur unter der Bedingung, dass er für sie Gründe angeben kann, kann sich seine Überzeugung als Wissen qualifizieren. Das Rechtfertigen durch Gründe ist eine Voraussetzung für Wissen und wird genau dadurch ermöglicht, dass Überzeugungen mit anderen Überzeugungen inferentiell in Zusammenhang stehen.

${ }^{221}$ Vgl. Rorty (1979), 178, BonJour (1985), 32 u. Davidson (1986), 310. 
Wissen ist damit in doppelter Hinsicht auf die inferentielle Gliederung der sprachlichen Praxis angewiesen. Einerseits ist etwas nur dann eine Überzeugung, wenn es für den Meinenden eine Bedeutung hat. Insofern ist etwas auch nur unter dieser Bedingung Wissen. Und Bedeutung wird nach der hier vertretenen Auffassung durch inferentielle Zusammenhänge konstituiert. Andererseits kann eine Überzeugung nur dann als Wissen ausgewiesen werden, wenn sich dafür rechtfertigende Gründe anführen lassen. Insofern müssen andere Überzeugungen als Rechtfertigung angeführt werden. Dies ist ebenfalls nur auf der Grundlage des inferentiellen Zusammenhangs, in dem die fragliche Überzeugung steht, möglich. Die rechtfertigende und die gerechtfertigte Überzeugung müssen inferentiell zusammenhängen. Somit greifen Bedeutungen und Rechtfertigungen auf ein und dieselbe sprachliche Infrastruktur zurück. Beide sind auf inferentielle Zusammenhänge angewiesen. Indem Wissen Bedeutung und Rechtfertigung voraussetzt, ist hierfür gleichermaßen die inferentielle Gliederung von Sprache eine Voraussetzung. Und in dem Maße wie das Meistern von inferentiellen Zusammenhängen eine praktische Fähigkeit ist, ist Können die Voraussetzung für Wissen.

\subsection{Nichtsprachliche Umstände und Folgen}

Mit inferentiellen Zusammenhängen steht und fällt die Gebrauchstheorie der Bedeutung. Sie bilden den strukturellen Hintergrund, vor dem sich der bedeutsame Gebrauch von Sprache abspielt. Wenngleich dies vorrangig sprachliche Zusammenhänge sind, so zeugen die erwähnten Wahrnehmungsberichte allerdings davon, dass die Umstände der bedeutsamen Verwendung einer Aussage auch nichtsprachlicher Natur sein können. Dies lässt sich auf die Folgenseite übertragen. Denn der Gebrauch einer Aussage kann ebenso gut außersprachliche Folgen haben. Ein Sprecher kann das Verständnis einer bestimmten Bedeutung prinzipiell auch dadurch signalisieren, dass er sich auf eine angemessene Weise verhält. In einem solchen Fall schließt er praktisch von der fraglichen Aussage auf eine bestimmte Handlung. Er zeigt dadurch, dass er mit einer Folge der Aussage vertraut ist, die allerdings außerhalb der Sprache liegt. Sagt er beispielsweise „Ich sollte diesen heißen Topf nur mit einem 
Topflappen anfassen.“, dann ist die Verwendung des Topflappens eine angemessene praktische Folge dieser Behauptung. ${ }^{222}$

Auch dieser Aspekt bildet auf semantischer Seite lediglich das ab, was auf pragmatischer Seite bereits Thema war. Bei der Erklärung praxisimpliziter Normen hatte der Begriff der externen Sanktion eine wichtige Bedeutung. ${ }^{223}$ Denn rein internes Sanktionieren kann die Unterscheidung von korrektem und inkorrektem Sprachgebrauch nicht regressfrei erklären. Die diskursive Praxis muss grundsätzlich in außersprachliche Handlungszusammenhänge eingebettet sein, soll sie als eine normative verständlich werden. Genau diese Einbettung sprachlicher in außersprachliche Zusammenhänge findet ihre Entsprechung auf der inferentiellen Ebene. Schließlich kann man eine Sanktion prinzipiell auch als die Folge einer Aussage begreifen. So wie es also auf der pragmatischen Seite internes und externes Sanktionsverhalten gibt, so gibt es auf der inferentiellen Seite inner- und außersprachliche Inferenzen.

Die Möglichkeit außersprachlicher Folgen darf also in einer Erklärung des angemessenen Gebrauchs von Aussagen ebenso wenig übergangen werden, wie die außersprachlicher Umstände. ${ }^{224}$ Die Rede vom inferentiellen Zusammenhang muss daher über das gewohnte, innersprachliche Verständnis hinaus ausgeweitet werden. Nimmt man alle Aspekte zusammen, dann bezieht sich der Begriff einmal auf die sprachlichen Umstände, aus denen eine Aussage folgt, dann auf die sprachlichen Folgen, die sie hat, weiter auf ihre nichtsprachlichen Umständen (Wahrnehmungsgegenstände) und schließlich auf ihre nichtsprachlichen Folgen (Handlungen). Mit anderen Worten, der inferentielle Zusammenhang einer Aussage setzt sich zusammen aus Sprachein-, Sprachüber- und Sprachausgängen. ${ }^{225}$

Hinsichtlich dieses erweiterten Verständnisses von inferentiellen Zusammenhängen sind Unklarheiten möglich. Die erste betrifft die Frage, inwiefern empirische Gegebenheiten als Spracheingänge bezeichnet werden können. Wieso müssen beispielsweise die Umstände eines

${ }^{222}$ Vgl. auch Brandom (1994), 233 ff.

${ }^{223}$ Vgl. Kap. 4.12.

${ }^{224}$ Zur Idee, diese beiden Möglichkeiten zu berücksichtigen, vgl. Sellars (1963b), §§ 18 ff. u. Brandom (1994), 119 ff., 131 ff. u. 233 ff.

${ }^{225}$ Vgl. Sellars (1963b), §§ 22 f. u. Sellars (1974), 423 f. 
Wahrnehmungserlebnisses Eingang in die Sprache finden, etwa in Form einer Aussage wie „Dies ist rot.“? Vollzieht sich die Rotwahrnehmung nicht ohne Sprache? Dies lässt sich durch die Möglichkeit, dass nichtsprachliche Folgen direkt auf nichtsprachliche Umstände folgen, noch weiter zuspitzen. Angenommen ein Autofahrer sagt, nachdem er eine rote Ampel wahrgenommen hat, zu seinem Beifahrer „Dies ist rot.“ und bringt seinen Wagen durch Bremsen zum Stehen. Seine Aussage hat also sowohl nichtsprachliche Umstände als auch nichtsprachliche Folgen. Soll all dies Teil des inferentiellen Zusammenhangs sein, der für die Bedeutung dieser Aussage konstitutiv ist?

All diese Fragen verdienen Zustimmung. Nicht nur stellen Wahrnehmungen Spracheingänge dar. Selbst Aussagen, deren angemessene Umstände und Folgen nichtsprachlicher Natur sind, stehen in inferentiellen Zusammenhängen. Es darf nicht vergessen werden, dass es auch hier um Bedeutung und nicht etwa um Reiz-Reaktions-Schemata geht. Wird also auf Unstände und Folgen rekurriert, dann immer mit Blick auf die Verwendung einer Aussage wie etwa „Dies ist rot.“ Ausgangspunkt für das Verständnis von Inferentialität ist stets der logische Raum der Gründe. Im geschilderten Fall wird dieser durch einen empirischpraktischen Raum der Gründe ergänzt, nicht aber ersetzt. ${ }^{226}$ Demnach geben die außersprachlichen Umstände und Folgen Grund zur Annahme, dass der Autofahrer die Bedeutung der Aussage „Dies ist rot.“ kennt.

Auch die Auffassung empirischer Gegebenheiten als Spracheingänge wird durch das Erklärungsziel einer inferentialistischen Bedeutungstheorie verständlich. Denn die Umstände des Sprachgebrauchs sind nur insofern Teil des inferentiellen Zusammenhangs, als sie Eingang in die Sprache finden. Es geht hier nicht einfach um außersprachliche Gegebenheiten wie Wahrnehmungen oder Empfindungen, sondern um Gegebenheiten, die Aussagen oder Überzeugungen wie beispielsweise „Dies ist rot.“ oder „Dieser Topf ist heiß.“ stützen oder hervorrufen. Es geht um Wahrnehmungs- oder Empfindungsüberzeugungen. Sollen Aussagen, die auf solche Gegebenheiten zurückgehen, eine Bedeutung haben, dann müssen auch sie unmittelbar Eingang in den inferentiellen Zusammenhang

${ }^{226}$ Vgl. hierzu auch erneut Heidegger (1993), 69 ff. 
anderer Aussagen finden. ${ }^{227}$ Nur so kann von bedeutsamem Wahrnehmen oder Empfinden gesprochen werden.

In semantischer Hinsicht ist Wahrnehmung immer eine sprachliche Angelegenheit. Denn das Entscheidende, was einem Detektor, einem Papagei oder einem Thermometer fehlt, ist die Fähigkeit, Gründe zu liefern oder zu fordern. Aussagen wie „Dies ist rot.“ oder „Dies ist ein Apfel.“ haben nur dann eine Bedeutung, wenn derjenige, der sie macht, auch darüber informiert ist, welche Schlüsse sich daraus ziehen lassen beziehungsweise welche Inferenzen sie stützen. Dies kann durchaus auch eine praktische Inferenz sein, durch die auf eine Handlung geschlossen wird. Auch hier wäre es jedoch falsch anzunehmen, jemand beherrsche die Bedeutung einer Aussage aufgrund einzelner oder isolierter Schlüsse. Von jemand, der auf eine Lautfolge wie „Dies ist rot.“ oder „Dies ist ein Apfel.“ mit nur einer einzigen Verhaltensweise reagiert, kann man nicht behaupten, er kenne ihre Bedeutung. Auch praktische Inferenzen setzen die Kenntnis eines gewissen „Spielraums“ voraus. In diesem Fall ist es ein Spielraum sinnvoller Handlungen. Andernfalls muss von Reaktionen statt von Inferenzen gesprochen werden.

Wahrnehmungen oder Empfindungen sind hier also nur insofern von Belang, als sie Gegenstand von Überzeugungen sind und als solche Eingang in die Sprache finden. Einer bedeutsamen Überzeugung Ausdruck verleihen heißt immer, einen Zug im Spiel des Gebens und Verlangens von Gründen zu machen. Der logische Raum der Gründe ist also primär ein diskursiver, inferentiell gegliederter Ort, wo Überzeugungen ausgedrückt werden, um Gründe zu geben und um nach Gründen zu fragen. Insofern ist eine Inferenz letztlich immer eine sprachliche Angelegenheit, auch wenn es hier Ein- und Ausgänge gibt. Dies gilt für das Gewahrwerden von Eigenschaften, Tatsachen oder Ähnlichkeiten, so wie es für das Folgern in Form von Handlungen gilt. Inferentielle Zusammenhänge sind letztlich immer sprachlich verankert.

Damit sind die beiden Faktoren, die den bedeutsamen Gebrauch eines Ausdrucks in einer Aussage bestimmen, umfassen erklärt. Wer eine Aussage richtig zu gebrauchen weiß, kennt zum einen die Umstände, unter

${ }^{227}$ Vgl. Sellars (1963a), insbes. $§ \S 16$ ff. u. 29 ff. Sellars bezeichnet diese Sichtweise als ,psychologischen Nominalismus“. Vgl. auch Bieri (1982), 3. 
denen ihre Verwendung angemessen ist. Zum anderen beherrscht er die Inferenzen, die der Gebrauch zur Folge hat. Erst wenn beide Faktoren berücksichtig werden, ist eine genaue Unterscheidung von Bedeutung und Referenz möglich. Mit der Berücksichtigung des gesamten inferentiellen Zusammenhangs lässt sich hier maximale Genauigkeit erreichen. So steht etwa die Verwendung einer Aussage, in der der Ausdruck „Morgenstern“ vorkommt, in einem anderen inferentiellen Zusammenhang als eine solche, in der der Ausdruck „Abendstern“ vorkommt. Gleiches gilt für Ausdrücke wie „Kaninchen“, „Zeitsegment eines Kaninchens“ und „Zusammenhängendes Kaninchenteil" sowie die oben problematisierte Unterscheidung von „Hase“ und „Eichhörnchen“. 228

Aus der Idee einer Gebrauchstheorie ergibt sich somit eine Semantik der inferentiellen Rolle oder einfach eine inferentielle Semantik. Danach sind die entscheidenden nicht-semantischen Gegebenheiten, von denen die semantischen Eigenschaften einer sprachlichen Äußerung abhängen, die inferentiellen Beziehungen zu anderen Äußerungen. Die inferentielle Rolle eines Satzes umfasst die Gesamtheit der Inferenzen, zu denen beizutragen er in der Lage ist. Zum spezifisch Inferentiellen der inferentiellen Rolle eines Satzes ist damit noch nicht viel gesagt. So lassen sich nun zwar die Regeln, die über die Korrektheit von Bedeutung bestimmen, als Inferenzregeln identifizieren. Allerdings können hier zwei Arten unterschieden werden: formale und materiale. Im verbleibenden Teil dieses Kapitels werde ich insbesondere auf die tragende Rolle materialer Inferenzregeln für das Projekt einer inferentiellen Semantik eingehen. Dadurch beabsichtige ich abschließend nachzuweisen, dass Wissen durch Können fundiert ist. Denn das Befolgen materialer Inferenzregeln ist eine praktische Fähigkeit, die maßgeblich für die Konstitution von Bedeutung und Rechtfertigung und somit letztlich auch für Wissen ist.

\subsection{Formale und materiale Inferenzen}

Eine Inferenz ist zunächst einmal nichts anderes als eine Schlussfolgerung oder auch einfach eine Folgerung oder ein Schluss. Ich

${ }^{228}$ Vgl. auch erneut Anm. 10 u. 206. 
werde im Folgenden nicht zwischen diesen Ausdrücken unterscheiden. Unkontrovers sind Beispiele wie die folgenden:

(12) Alle Autofahrer sind Teilnehmer des öffentlichen Straßenverkehrs. Alle Teilnehmer des öffentlichen Straßenverkehrs sind an die StVO gebunden. Somit sind alle Autofahrer an die StVO gebunden.

(13) Wenn Karl Hannah wirklich liebt, dann wird er ihr verzeihen. Karl liebt Hannah wirklich. Also wird er ihr verzeihen.

(14) Es stimmt nicht, dass sie die Uhr nicht genommen hat. Also hat sie die Uhr genommen.

Dass es sich hierbei um Schlussfolgerungen handelt, lässt sich anhand der logischen Konstanten ,alle“, „somit“, „wenn ... dann“ oder ,also“ erkennen. Dies kann sogar noch deutlicher sein, wenn beispielsweise Ausdrücke wie „,folglich“, ,infolgedessen“ oder ,,daraus folgt“ explizit auf Schlussfolgerungen hinweisen. Anders als logische Subjekte, Prädikate, Adverbien etc. haben logische Konstanten keine deskriptive oder repräsentative Funktion. Was den Inhalt von Sätzen anbelangt, sind sie neutral. $^{229}$ Vielmehr haben sie eine expressive oder pragmatische Bedeutung. Sprecher, die sie verwenden, vermitteln Informationen, die die logische Funktion der jeweiligen Sätze betrifft. Diese bleibt auch bei wechselnden Inhalten konstant. Dadurch können logische Konstanten ein Hinweis darauf geben, dass eine spezielle Abfolge von Sätzen den Status einer Inferenz hat. Das Vorkommen von Ausdrücken wie „,somit“, „,also“, „folglich“, „deshalb“, „,aufgrund dessen“ etc. verweisen beispielsweise auf den Übergang von einer oder mehreren Prämissen zu einer Konklusion. ${ }^{230}$

Inferenzen lassen sich also aufgrund formaler Merkmale direkt als solche erkennen. Mit Hilfe logischer Konstanten lässt sich die Struktur einer bestimmten Reihe von Sätzen als eine Inferenz identifizieren. Doch eine Inferenz ist mehr als ein rein grammatisches Phänomen. Sie hat eine spezifische logisch-argumentative Kraft. Sprecher, die Schlussfolgerungen anstellen, machen sich die Tatsache zu eigen, dass sich Sätze oder

${ }^{229}$ Aus Gründen der Übersichtlichkeit rede ich im Folgenden vorwiegend von Sätzen statt von Satzteilen.

${ }^{230} \mathrm{Zu}$ der Lesart, wonach allein eine Konklusion eine Schlussfolgerung, die Kombination aus Prämissen und Konklusion dagegen ein Argument ist, vgl. auch Salmon (1983), 7 ff. 
Aussagen auf eine relevante und notwendige Weise aufeinander beziehen können. Dies steht jedoch nicht allein dadurch fest, dass eine Satzfolge eine bestimmte logische Konstante enthält. Nicht jeder Übergang von einer Prämisse zu einer Konklusion ist auch gleichzeitig ein gültiger Schluss beziehungsweise eine korrekte Inferenz. ${ }^{231}$ Mit anderen Worten, eine Inferenz ist immer auch Gegenstand der Beurteilung. Betrachten wir beispielsweise die folgenden Aussagen:

(15) Einige von denen, die nicht glauben, dass Gott die Welt in sieben Tagen geschaffen hat, sind keine Fundamentalisten. Einige Fundamentalisten glauben, dass Gott die Welt in sieben Tagen geschaffen hat. Also ist keiner, der nicht glaubt, dass Gott die Welt in sieben Tagen geschaffen hat, ein Fundamentalist. ${ }^{232}$

Der Ausdruck ,also“ lässt vermuten, dass dies eine Inferenz ist. Ob sie aber auch korrekt ist, ist damit noch nicht garantiert. Für korrekte Inferenzen gilt, dass die Konklusion mit logischer Notwendigkeit aus den Prämissen folgt. Gültige Schlüsse zeichnen sich dadurch aus, dass sie einen zwingenden Charakter haben. Wann aber ist das der Fall?

Eines der grundlegendsten Ziele der Logik ist die Unterscheidung korrekter von inkorrekten Inferenzen. Um dieses Ziel $\mathrm{zu}$ erreichen, versuchen Logiker, Kriterien ausfindig zu machen, die ein korrektes oder gültiges Schlussfolgern ermöglichen. So gilt beispielsweise grundsätzlich, dass aus wahren Prämissen nur wahre Konklusionen abgeleitet werden können. ${ }^{233}$ Zwar müssen die Prämissen eines gültigen Schlusses nicht immer wahr sein. Auch aus falschen Prämissen lassen sich Schlüsse ziehen. Eine Inferenz gilt jedoch als inkorrekt, wenn die Prämissen wahr sind, die Konklusion aber falsch ist. Einem anderen Prinzip zufolge kann eine Inferenz niemals korrekt sein, wenn ihre Prämissen partikulare Aussagen sind, ihre Konklusion aber eine allgemeine Aussage ist. ${ }^{234}$ Insofern stellt (15) keine korrekte Inferenz dar. Denn darin kommen nur partikulare Prämissen vor.

${ }^{231}$ Ich verzichte hier auf eine prinzipielle Unterscheidung zwischen Korrektheit und Gültigkeit.

${ }^{232} \mathrm{Zu}$ diesem Beispiel vgl. Eco (1989), 81.

${ }^{233}$ Vgl. Whitehead/Russell (1910), 94.

${ }^{234} \mathrm{Vgl}$. Arnauld/Nicole (1965), $183 \mathrm{f}$. 
Die Logik ist erklärtermaßen nicht interessiert an dem, worum es in den untersuchten Sätzen geht. ${ }^{235}$ Sie versteht sich als eine rein formale Wissenschaft. Ob eine Inferenz korrekt ist, soll sich unabhängig vom Gegenstand der fraglichen Prämissen und Konklusionen zeigen lassen. Es geht ihr nicht um die einzelnen Sätze, sondern um den Transport und Erhalt ihrer Wahrheitswerte. Daher wird eine Inferenz auch nicht als wahr oder falsch, sondern als korrekt oder inkorrekt bezeichnet. Eine korrekte Inferenz ist nicht wahr, sondern wahrheits(wert)erhaltend. Anhand formaler Merkmale lässt sich demnach nicht nur herausfinden, dass eine bestimmte Reihe von Sätzen einer Inferenz ähnelt. Auch ihre Korrektheit ist daraus ableitbar. Diese lässt sich vielfach bereits danach beurteilen, ob eine Satzreihe einem bestimmten Muster oder Schema entspricht. Gegebenenfalls repräsentiert dies ein formales Prinzip, dessen Geltungsbereich sich über alle Satzreihen dieses Typs erstreckt. So lässt sich (15) anhand seines formalen Aufbaus leicht als ungültiger Schluss entlarven. Kenntnisse über Theologie und Fundamentalismus sind hier nicht erforderlich.

Die auf das Formale konzentrierte Analyse braucht sich um den Inhalt der jeweiligen Aussagen nicht zu kümmern. Das kann die Beurteilung der entsprechenden Inferenz erleichtern. Denn ob der Schluss von einer Reihe von Prämissen auf eine Konklusion auf angemessene und berechtigte Weise erfolgt, lässt sich häufig nicht so leicht feststellen. Natürliche Sprachen können sehr komplex und mehrdeutig sein. Die Korrektheit oder Inkorrektheit einer Inferenz kann sich dem Blick leicht entziehen. Davon zeugt Beispiel (15). Mögen erste Indizien auch auf eine Inferenz hinweisen. Ob mit bestimmten logischen Konstanten auch tatsächlich eine korrekte Inferenz vorliegt, ist damit jedoch noch nicht ausgemacht.

Für eine einfache und verlässliche Beurteilung von Inferenzen arbeitet die Logik mit den Mitteln der Abstraktion und der Formalisierung. Dies ermöglicht deren systematische und schematische Analyse nach ausschließlich formalen Kriterien. So wird auch für komplexe Fälle schnell ersichtlich, ob eine bestimmte Abfolge von Sätzen einer anerkannten, gültigen Schlussform entspricht, ob also die Inferenz- oder Schlussregeln beziehungsweise die Gesetze der Logik eingehalten werden. So hat

${ }^{235}$ Vgl. z. B. Salmon (1983), 12 o. Wessel (1998), 5. 
beispielsweise (12) die Form des Modus Barbara beziehungsweise des Kettenschlusses, (13) die des Modus Ponens beziehungsweise der Abtrennungsregel und (14) die des Gesetzes der Doppelten-NegationsBeseitigung. ${ }^{236}$ Satzfolgen, die sich als Anwendungen solcher, anerkanntermaßen gültiger Schlussformen, -regeln oder -gesetze ausweisen lassen, können immer als korrekte Inferenzen gelten. Eine Deutung oder ein Verständnis der einzelnen Sätze ist dabei überflüssig.

Somit lassen sich Inferenzen, deren Korrektheit allein von formalen Kriterien abhängt, als formale Inferenzen bezeichnen. Eine gegebene Satzmenge ist eine formale Inferenz, wenn sie der Form nach als eine solche erkennbar ist. Logische Konstanten geben darauf einen Hinweis. Formale Schlussregeln ermöglichen zudem die Unterscheidung von korrekt und inkorrekt beziehungsweise gültig und ungültig. Aus der Einhaltung formalen Regeln ergibt sich die formale Gültigkeit oder Korrektheit einer Inferenz. Sie ist ausschließlich eine Funktion der Form. Dadurch hat sie universale Geltung. Sie ist auf alle Einzelfälle übertragbar, die dieselben formalen Merkmale aufweisen. Aufgrund ihrer Transparenz und Evidenz gelten formale Inferenzen als sehr sicher. Für einen Sprecher stellt es kein besonderes Risiko dar, einen Satz zu billigen, wenn auf ihn beispielsweise mit Hilfe des Kettenschlusses geschlossen wurde. Zusätzliche Annahmen, die sich möglicherweise als falsch herausstellen, sind hier nicht nötig. Als eine ihrer zentralen Aufgaben betrachtet die Logik daher das Aufstellen und Systematisieren formaler Schlussregeln. ${ }^{237}$

Die Wissenschaft ist ohne die Praxis des Schlussfolgerns nicht denkbar. Und auch der alltägliche Diskurs ist davon geprägt. Insbesondere außerhalb des wissenschaftlichen Diskurses kommen aber häufig auch Inferenzen zum Einsatz, die sich nicht durch ihre Form als solche zu erkennen geben. So schließen wir beispielsweise von „Der Mord geschah am Mittwoch.“ auf „Am Dienstag war das Opfer noch am Leben.“, von „Er wurde von einem Priester getauft.“” auf „Jetzt ist er ein Christ.“ oder von „Berlin liegt östlich von Hamburg.“ auf „Hamburg liegt westlich von Berlin." In diesen Fällen gibt es keine formalen Hinweise darauf, dass es sich um Schlussfolgerungen handelt. Es ist zwar möglich, die zweite

\footnotetext{
${ }^{236}$ Vgl. auch Aristoteles (1995), 6 u. Whitehead/Russell (1984), 18.

${ }^{237}$ Vgl. z. B. Wessel (1998), 6.
} 
Aussage jeweils durch einen Ausdruck wie „also“ oder „folglich“ zu ergänzen. Dies ist aber nicht zwingend nötig. Prinzipiell verfügen derartige Inferenzen über keine formalen Merkmale, die sie als solche ausweisen. Was die betreffenden Sätze angeht, unterscheiden sie sich nicht von Satzfolgen, die keine Inferenzen sind.

Dass es sich dennoch um Schlussfolgerungen handelt, ist nicht der logischen Form der Sätze oder ihrer Abfolge geschuldet. Der inferentielle Zusammenhang dieser Sätze ergibt sich vielmehr aus ihrem jeweiligen semantischen Gehalt. Sie bilden Schlussfolgerungen, weil das, worum es geht, inhaltlich oder material zusammenhängt. So sind es insbesondere die Bedeutungen der Ausdrücke „Mittwoch“ und „Dienstag“, „getauft“ und „Christ“ oder „östlich“ und „westlich“, die dafür sorgen, dass die entsprechenden Aussagen in einer logisch relevanten Beziehung zueinander stehen. Sie sind es, die den inferentiellen Zusammenhang dieser Aussagen herstellen. Daher lassen sich Inferenzen, die auf dem Gehalt von Aussagen beruhen, als ,materiale Inferenzen“ bezeichnen. ${ }^{238}$

Auch für materiale Inferenzen gilt aber, dass sie korrekt oder inkorrekt sein können. Auch sie sind grundsätzlich Gegenstand der Beurteilung. Ihre Korrektheit ergibt sich aber nicht aus der Übereinstimmung mit anerkannten Inferenz- oder Schlussregeln. Diese Methode steht offenkundig nicht zur Verfügung. Denn es gibt keine formalen Merkmale, die für ihre Beurteilung berücksichtigt werden können. Materiale Inferenzen weisen keine charakteristischen Schemata auf. Logische Ausdrücke kommen nicht notwenig vor. Auch Abstraktionen oder Formalisierungen sind nicht möglich. Alles, was sich in formaler Hinsicht zeigen lässt, ist das zeitlich zusammenhängende Vorkommen zweier Aussagen. Dies aber ist wenig aufschlussreich. Für die Korrektheit materialer Inferenzen gilt daher dasselbe wie für ihren Status als Inferenzen überhaupt. Ausschlaggebend ist nicht die Übereinstimmung mit formalen Regeln oder Mustern, sondern das, worum es in den Sätzen geht. Die Korrektheit materialer Inferenzen hängt vom jeweiligen Inhalt der Prämissen und Konklusionen ab.

\footnotetext{
${ }^{238}$ Vgl. Sellars (1953) u. Sellars (1963b), 331 f. Während sich Sellars Überlegungen jedoch auf die subsententiale Ebene begrifflicher Gehalte beziehen, ist für mich auch hier die primäre Betrachtungsebene die ganzer Sätze und somit propositionaler Gehalte.
} 
Das macht diese Art von Inferenz interessant. Denn die Idee der Gebrauchstheorie der Bedeutung ist ja im Kern die, dass der inferentielle Zusammenhang einer Aussage ihre Bedeutung bestimmt. Würde man nun Inferenzen primär als formale verstehen, so bliebe dieser bedeutungstheoretische Anspruch größtenteils auf der Strecke. Denn formale Inferenzen sind ausdrücklich nicht am Gehalt von Aussagen interessiert. Sie sind semantisch gesehen neutral, wenn nicht uninformativ. Beim Modus Ponens etwa entsteht die Konklusion durch das Abtrennen des Antezedens eines Konditionals. Somit ist der Gehalt der Konklusion in den Prämissen bereits enthalten. Er bleibt in der Schlussfolgerung unverändert und wird durch die Regel lediglich betont oder explizit gemacht. Auch beim Modus Barbara ist die Konklusion nur eine inhaltsgleiche Variante der Prämissen. Durch Verkettung wird ein Prädikat von den Prämissen zur Konklusion übertragen. Und dass die DoppelteNegations-Beseitigung gehaltsneutral ist, ist offensichtlich. In formalen Inferenzen vollzieht sich also lediglich eine formale Umwandlung der Prämissen in die Konklusion. Daher auch ihre Bezeichnung als „Transformations- oder Umformungsregeln“. 239

Der bedeutungstheoretische Rückgriff auf Inferenzen muss jedoch berücksichtigen, worum es in den Aussagen inhaltlich geht. Er kann sich nicht ausschließlich auf rein formale Aspekte des Übergangs von Prämissen zu Konklusionen beschränken. Nur für materiale Inferenzen gilt aber, dass sie Gehalte thematisieren und Auskunft über Bedeutungen geben. Daher scheint es naheliegend, sie zur Grundlage der Untersuchung zu machen. Der kritische Leser mag aber fragen, ob sich diese Erklärung nicht im Kreis dreht. Wenn materiale Inferenzen auf der einen Seite von Bedeutung abhängen, dann kann Bedeutung auf der anderen Seite schlecht durch materiale Inferenzen bestimmt werden. Es entsteht der Eindruck, dass die Anwendung des Begriffs der materialen Inferenz zur Erklärung von semantischem Gehalt schlichtweg zirkulär ist. Dieser Verdacht lässt sich jedoch ausräumen, indem man noch einmal an die generelle Systematik dieser Arbeit erinnert. Die Idee der Gebrauchstheorie der Bedeutung, aus der ich die bisherigen Überlegungen entwickelt habe,

${ }^{239}$ Vgl. z. B. Wittgenstein (1984a), 231 u. 331, Carnap (1968), 2 u. 25 o. Sellars (1953), $318 \mathrm{ff}$. 
beinhaltet ja die Strategie, eine Semantik auf einer Pragmatik aufzubauen. Der explanatorische und systematische Ausgangspunkt dieses Ansatzes ist der Gebrauch von Sprache. Und dieser ist wie gesehen immer implizit normativ. Vor diesem Hintergrund müssen nun auch materiale Inferenzen gesehen werden. Diese sind dann insofern korrekt oder inkorrekt, als sie von Sprechern in der diskursiven Praxis als korrekt oder inkorrekt betrachtet und behandelt werden. Indem also Bedeutung und semantische Korrektheit auf die normative Pragmatik zurückgeführt wird, wird ein explanatorischer Zirkel vermieden.

\subsection{Die Normativität von Inferenzregeln}

Formale Inferenzen sind korrekt, wenn sie mit formalen Inferenzregeln übereinstimmen. Steht der Übergang einer gegebenen Satzfolge formal mit einer anerkannten Regel in Einklang, so folgt die Konklusion mit strikter Notwendigkeit und absoluter Gewissheit aus den Prämissen. Formale Inferenzregeln sind logisch zwingend in einem strengen Sinne. Sie lassen keinen Spielraum für Abweichungen, was die jeweilige logische Folge angeht. Unter dieser Voraussetzung kann man nun fragen, ob es sich hier überhaupt noch um Regeln im erforderlichen Sinne handelt. ${ }^{240}$ Ziel dieser Untersuchung ist es schließlich, inferentielle Zusammenhänge als Grundlage für die Bestimmung von Bedeutung verständlich zu machen. Dabei geht es nicht darum, Inferenzen gemäß bestimmter Standards, Ideale oder Normalfälle zu klassifizieren. Inferenzregeln werden also nicht als Gegenstandsnormen aufgefasst. Vielmehr sollen sie Kriterien für den korrekten Sprachgebrauch sein, durch den sich dann wiederum Bedeutung konstituiert. Sie müssen also Handlungsnormen sein. ${ }^{241}$ Aufgrund ihres zwingenden Charakters ist es aber zweifelhaft, ob Inferenzregeln tatsächlich Regeln dieses Typs sein können. Vielmehr scheint es, als können sie sich überhaupt nicht auf Handlungen beziehen. Schließlich sind das Anderskönnen, das Unterlassen sowie das Scheitern wesentliche Bestandteile des Handlungsbegriffs. ${ }^{242}$

\footnotetext{
${ }^{240}$ Vgl. Glüer (1999b), 201 u. Tietz (2003), $73 \mathrm{f}$.

${ }^{241}$ Vgl. erneut Kap. 3.4.

${ }^{242}$ Vgl. erneut Anm. 95.
} 
Nur in diesem Sinne ist es überhaupt sinnvoll, Handlungen durch Regeln steuern zu wollen. Was nicht unterlassen werden kann, kann auch nicht geregelt, geschweige denn ge- oder verboten werden. Verletzbarkeit ist eine notwendige Bedingung für handlungsleitende Regeln.

Soll das Schlussfolgern also eine regelgeleitete Art des Handelns sein, so muss es auch hier prinzipiell möglich sein, die entsprechenden Regeln $\mathrm{zu}$ verletzen. Es muss möglich sein, das Befolgen auch zu unterlassen oder daran zu scheitern. Dies wird aber durch den logischen Zwang, der zumindest von formalen Inferenzregeln ausgeht, verhindert. Denn dieser schließt jede Möglichkeit, sich anders zu entscheiden, aus. ${ }^{243} \mathrm{Zu}$ dem, wie etwas logisch aus etwas anderem folgt, gibt es streng genommen keine Alternative. Ich kann mich nicht entschließen, es nicht zu folgern, wenn mir gerade der Sinn danach steht. Wollte man Inferenzregeln daher als handlungsleitend begreifen, dann müsste es beim Schlussfolgern überhaupt erst einmal eine Wahl geben, die dann durch den logischen Zwang zunichte gemacht werden kann. Offensichtlich ist es beim logischen Schließen aber so, dass wir diese Wahl gerade nicht haben. Wenn es aber gar nicht möglich ist, sich anders zu verhalten, dann ist es auch nicht sinnvoll, vom Befolgen von Regeln zu sprechen.

Wie man es auch wendet, etwas scheint hier nicht zu stimmen. Entweder werden Inferenzen überhaupt nicht durch Regeln geleitet. Dann muss die Rede von Inferenz- oder Schlussregeln unsinnig erscheinen oder kann bestenfalls metaphorisch verstanden werden. Oder Inferenzen werden sehr wohl durch Regeln geleitet. Dann kann es sich aber nicht um Handlungsnormen handeln, die angeben, was wir tun sollen. Wir müssten also davon ausgehen, dass sie keinerlei normative Kraft haben, sondern vielmehr eine Art Gegenstandnorm sind. Kurzum, wenn wir an einem nicht-metaphorischen Verständnis von Inferenzregeln festhalten wollen, müssen wir ihren Status als Regel klären. Somit lässt sich diese erste Frage als eine nach der Normativität von Inferenzregeln präzisieren.

Um hier zu einer Lösung zu kommen, kann man das Problem von zwei Seiten angehen. Zum einen ist es möglich, den Gegenstand von

${ }^{243}$ Vgl. Wittgenstein (1984a), 37 ff., 50 ff., 79 ff. o. 187 ff. Wittgenstein redet auch von der „Härte des logischen Muß“. Vgl. Wittgenstein (1984a), 84 u. 352 u. Wittgenstein (1984d), § 437. 
Inferenzregeln einer genaueren Untersuchung $\mathrm{zu}$ unterziehen. Dies erfordert es, sich mit dem Inferenz-Teil des problematischen Begriffs näher $\mathrm{zu}$ befassen. Es gilt zu klären, für welche Art von Inferenz das Gesagte eigentlich gilt. Zugleich muss herausgefunden werden, ob Inferenzen etwas mit Handlungen zu tun haben oder nicht. Zum anderen kann man sich um eine Präzisierung der Art und Funktionsweise von Inferenzregeln bemühen. Hier steht der Regel-Teil im Fokus. Spätestens hier ist dann auch eine Antwort auf die Normativitätsfrage zu erwarten. Soweit sich die beiden Teile überhaupt voneinander trennen lassen, werde ich auf sie in der genannten Reihenfolge eingehen.

\subsection{Der Inferenz-Teil von Inferenzregeln}

Die Rede vom logischen Zwang gilt zunächst einmal uneingeschränkt für formal gültige Schlüsse. Wenn wir sagen, ein Schluss sei logisch zwingend, so beziehen wir uns damit in erster Linie auf diese Art von Inferenz. Für sie oder vielmehr für die Regeln, mit denen sie übereinstimmen, gilt, dass sie in einem strengen Sinne zwingend und notwendig sind. Bei materialen Inferenzen verhält es sich dagegen anders. Hier kann von einem logischen Zwang nicht die Rede sein. Wenn wir in diesem Zusammenhang von einem notwendigen Übergang von Prämissen zu Konklusionen sprechen, dann nicht in demselben strengen Sinn wie bei formalen Inferenzen. Die Rede von der Notwendigkeit materialer Inferenzen und der damit einhergehenden Regeln muss daher abgeschwächt werden. Wir müssen zwischen formaler und materialer Notwendigkeit unterscheiden. ${ }^{244}$ Nur für erstere gilt, dass sie strikt, zwingend und absolut ist.

Formale Inferenzen sind notwendig aufgrund der strengen Vorgaben der entsprechenden Regeln. Ihre jeweilige Form ist eindeutig bestimmt. Soll beispielsweise nach dem Modus Ponens logisch korrekt geschlossen werden, dann ist genaue eine Konklusion möglich, nämlich das Konsequens des Konditionals. Die Notwendigkeit, mit der sich ein solcher Schluss vollzieht, und die Korrektheit, die daraus resultiert, ist daher eine eindeutige Angelegenheit. Entweder eine formale Inferenz stimmt völlig

\footnotetext{
${ }^{244}$ Vgl. auch Sellars (1953). Sellars diskutiert diese Unterscheidung allerdings nicht.
} 
mit der entsprechenden Regel überein oder überhaupt nicht. Es gibt keine Grade formaler Korrektheit oder Gültigkeit. Daher gibt es keine Möglichkeit, der Regel nicht $\mathrm{zu}$ folgen und sie, wie eine echte Handlungsanweisung, zu verletzen. Ein „Fehlschluss“ ist daher genau genommen überhaupt kein Schluss. ${ }^{245}$ Was wir tun, wenn wir beispielsweise sagen „Wenn Karl sie wirklich liebt, dann wird er ihr verzeihen. Karl liebt sie wirklich. Also wird er ihr nicht verzeihen." ist unlogisch und kann nicht als Schlussfolgerung gelten.

All das gilt für materiale Inferenzen nicht in gleichem Maße. Hier ist die Form gerade nicht maßgeblich. Aus „Der Mord geschah am Mittwoch.“ folgt in materialer Hinsicht „Am Dienstag war das Opfer noch am Leben." Denn dies ist die korrekte Verwendung von Ausdrücken wie „Mittwoch“, „Dienstag“, „Mord“ und „Leben“. Dass wir einen solchen Schluss ziehen, ist aber nicht logisch zwingend. In einer vergleichbaren formalen Inferenz würden wir vielleicht zu einer Konklusion kommen wie: „Also ist es nicht der Fall, dass der Mord nicht am Mittwoch geschah.“, vorausgesetzt wir wenden die Regel der Doppelten-Negations-Einführung an. Dies würde dann durchaus mit strikter Notwendigkeit gelten und keinerlei Abweichung erlauben. Bei materialen Inferenzen kann davon jedoch keine Rede sein.

Während es bei formalen Inferenzen keine Alternative zur Konklusion gibt, stehen bei materialen Inferenzen verschiedene Möglichkeiten offen. Es gibt hier kein eindeutiges Schema oder Muster, das auf genau die eine Konklusion festlegt. Die Notwendigkeit, mit der wir Schlüsse dieser Art ziehen, ist nicht absolut. Natürlich steht es mir nicht vollkommen frei, worauf ich beispielsweise von „Der Mord geschah am Mittwoch.“ schließe. Konklusionen wie „Der Mord geschah am Dienstag.“ oder „Am Mittwoch war das Opfer noch am Leben." stehen nicht zur Verfügung. Denn dies sind keine legitimen Verwendungsweisen der involvierten Ausdrücke und Aussagen. Derartige Inferenzbeziehungen sind material unvereinbar. Es gibt hier jedoch einen gewissen Handlungsspielraum, weshalb man auch von Graden der Notwendigkeit sprechen kann. In

${ }^{245}$ Vgl. Frege (1966), XVI. Frege bezeichnet Verstöße gegen die formalen Regeln des logischen Schließens als „eine bisher unbekannte Art der Verrücktheit“. Vgl. auch Wittgenstein (1984a), 80 f., 96 f. u. 239 u. von Wright (1963), 3 ff. 
Abhängigkeit von Gehalt oder Bedeutungsumfang einer Prämisse sind daher stets verschiedene Konklusionen möglich.

Damit ist einerseits gemeint, dass der formale Aufbau materialer Inferenzen eben nicht von vorne herein vorgegeben ist. Was aus einer Aussage material folgt, ist nicht eindeutig festgelegt oder an ein bestimmtes Schema gebunden. Von daher ist es zwar legitim, in materialer Hinsicht korrekte Übergänge als notwendig zu bezeichnen. Denn das Gefolgerte hängt inhaltlich unmittelbar mit dem zusammen, woraus es gefolgert wird. Es sind aber stets Alternativen und Abweichungen möglich. So ist zwar der Schluss von „Der Mord geschah am Mittwoch.“ auf „Am Dienstag war das Opfer noch am Leben." korrekt. Es sind aber durchaus auch andere Schlüsse denkbar, die auf vergleichbare Weise als notwendig bezeichnet werden können. So kann man auch zu dem Schluss kommen: „Am Donnerstag war das Opfer bereits tot.“ oder „Am Mittwoch wurde ein Verbrechen begangen." Jede dieser Folgerungen ist in materialer Hinsicht gültig. Keine von ihnen ist aber in einem streng logischen Sinn zwingend.

Andererseits ist gemeint, dass Prämissen Konklusionen in materialen Inferenzen unterschiedlich stark stützen. Man kann hier von Graden der Folgerichtigkeit oder der Wahrscheinlichkeit sprechen. Vorausgesetzt, die Folgebeziehung ist in einem materialen Sinn relevant und notwendig, so ist in vielen Fällen eine graduelle Unterscheidung möglich. Beispielsweise ist der Grad der Folgerichtigkeit bei dem Schluss von „Berlin liegt östlich von Hamburg.“ auf „Hamburg liegt westlich von Berlin.“ höher als bei dem Schluss von „Es blitzt.“ auf „Bald wird Donner zu hören sein.“ Denn im zweiten Fall hängt die Gültigkeit der Schlussfolgerung neben der Bedeutung der Aussagen zusätzlich von meteorologischen Gegebenheiten ab. Im ersten Fall dagegen müssen keine weiteren Gegebenheiten oder Annahmen berücksichtigt werden. Stark vereinfacht könnte man auch sagen, dass „Donner“ aus „Blitz“ mit geringerer Notwendigkeit folgt, als „westlich“ aus „östlich“. ${ }^{246}$

Was den Inferenz-Teil von Inferenzregeln angeht, so lässt sich also ein wichtiger Unterschied feststellen. Formale Inferenzen sind logisch zwingend und absolut notwendig. Materiale Inferenzen dagegen lassen einen Spielraum zu, was die jeweilige Konklusion betrifft. Das erlaubt eine

${ }^{246}$ Vgl. auch Kap. 5.15. 
erste Prognose hinsichtlich der Frage, ob Inferenzregeln sich auf Handlungen beziehen, ob sie also als Handlungsnormen gelten können. So macht die Tatsache, dass sie in einem strengen Sinne logisch zwingend sind, formal gültige Inferenzen als Kandidaten untauglich. Wenn für Handlungen die Möglichkeit des Anderskönnens, Unterlassens oder Scheiterns gegeben sein muss, dann kommen sie nicht in Frage. Denn die einzig denkbare Abweichung ist die, überhaupt keine Schlussfolgerung anzustellen. Dieses Ganz-oder-gar-nicht lässt offensichtlich nicht den nötigen Spielraum, der handlungsleitende Regeln ausmacht. Material gültige Inferenzen sind dagegen immer auch anders als im konkreten Fall denkbar. Hier gibt es stets ein Spektrum an Alternativen, auf die geschlossen werden kann. Dabei ist offen, welche Aussagen konkret in Beziehung zueinander gebracht werden. Dies ergibt sich daraus, worum es im Einzelnen inhaltlich geht.

Aus diesem Grund ist beim materialen Schließen auch die Rede vom Scheitern sinnvoll. Die Grenze zwischen korrekt und inkorrekt ist hier nicht automatisch die zwischen Schluss und kein Schluss. Nur wer den inferentiellen Zusammenhang übermäßig strapaziert, verlässt den Bereich dessen, was noch sinnvoll und bedeutsam ist. Nur der schlussfolgert überhaupt nicht mehr, sondern verabschiedet sich aus dem rationalen Diskurs und redet stattdessen Unsinn. Die Grenze dessen, was noch bedeutsam ist, ist aber nicht schon bei der geringsten formalen Abweichung überschritten. Im Gegenteil ist ein Anderskönnen essentiell dafür, dass Bedeutung vermittelbar ist. Nur weil es unterschiedliche inferentielle Zusammenhänge gibt, ist das Verständnis einzelner Ausdrücke überhaupt möglich. Zugleich sorgt dieser Bereich des Anderskönnens dafür, dass materiale Inferenzregeln auf eine plausible Weise verletzbar sind. Insofern bringt diese Art von Regeln tatsächlich ein handlungsleitendes Sollen zum Ausdruck. Denn materiales Schlussfolgern ist eben genau dies: sprachliche Praxis.

\subsection{Der Regel-Teil von Inferenzregeln}

Damit ist die Untersuchung längst in den Regel-Teil der Problematik vorgedrungen. Daher wende ich mich nun der genaueren Spezifikation von Inferenzregeln zu. Die Frage war, ob es sich hierbei überhaupt um 
normative oder handlungsleitende Regeln handelt. Und eine erste Antwort lautete: Unter der Bedingung, dass Schlussfolgern eine Form des Handelns ist, ist dies durchaus möglich. Formale Inferenzen erfüllen diese Bedingung aus den genannten Gründen nicht. Bleibt das materiale Schließen. Um nun $\mathrm{zu}$ verstehen, inwiefern es sich hierbei um eine regelgeleitete Praxis handelt, lässt sich auf frühere Unterscheidungen zurückgreifen. Denn die Frage nach der Normativität hat sich bei der differenzierenden Bestimmung des Regelbegriffs in Kapitel 3.4 schon einmal gestellt. Dort war die Antwort, dass die normative Kraft sprachlicher Regeln nur dann in Frage steht, wenn sie als Präskriptionen aufgefasst werden und wenn nicht zwischen semantischer und empirischer Korrektheit unterschieden wird. Ich habe daher vorgeschlagen, sie stattdessen als konstitutive Regeln im Searleschen Sinne zu verstehen und die unterschiedlichen Formen der Korrektheit zu berücksichtigen.

Wie gesehen sind auch Inferenzregeln konstitutiv für das, was sie zum Gegenstand haben. Mit Searle kann man auch sagen, dass das materiale Schließen von ihnen „logisch abhängig“ ist. Was dies betrifft sind Inferenzregeln mit den Regeln des Schachs oder des Fußballs vergleichbar. Ihre Abwesenheit oder ihr systematisches Ignorieren bedeutet auch hier die Abwesenheit oder das Verschwinden der Praxis selbst. Die normative Kraft konstitutiver Regeln besteht nun darin zu sagen, unter welchen Bedingungen etwas als eine regelgeleitete Praxis gilt oder nicht. Sie fordern oder erlauben eine bestimmte Vorgehensweise in Bezug auf bestimmte Umstände. ${ }^{247}$ Und in genau diesem Sinne sind Inferenzregeln für die Praxis des Schlussfolgerns konstitutiv. Insofern stellen sich die Bedenken hinsichtlich ihrer Normativität zumindest teilweise als unbegründet heraus. Für formalen Inferenzen gilt dies natürlich nach wie vor nicht. Auch wenn wir das formal-logische Schließen beispielsweise als das Aufschreiben oder Überprüfen eines Kalküls oder das Formalisieren eines Arguments verstehen, verhindert die strikte Notwendigkeit formaler Inferenzregeln, dies als eine genuin regelgeleitete Praxis aufzufassen. Insofern ist ausgeschlossen, dass hierbei handlungsleitenden Regeln

${ }^{247}$ Zur Unterscheidung von konstitutiven Regeln und Präskriptionen vgl. erneut Kap. 3.4. Zu einer ganz ähnlichen Bestimmung ,syntaktischer Regeln“ vgl. Sellars (1953), 330. 
gefolgt wird. Schlussfolgern kann nur dann Regelfolgen sein, wenn es sich um materiale Inferenzen handelt.

Wenn man also materiale von formalen Inferenzregeln auf die vorgeschlagene Weise unterscheidet und sie zugleich als konstitutive Regeln begreift, dann lassen sie sich durchaus der Klasse der handlungsleitenden Regeln zuordnen. Das erklärt sich zunächst durch ihre allgemeine Funktion, korrekt und inkorrekt zu unterscheiden. Das macht sie überhaupt erst einmal zu Regeln. Handlungsleitend sind sie darüber hinaus in dem Sinne, dass sie sich auf die sprachliche Praxis beziehen. Ihre spezielle Funktion ist die Konstitution von Bedeutung. Sie geben an, was es heißt, sprachliche Performanzen derart auszuführen, dass sie ihre jeweilige Bedeutung haben. Und sie tun dies, indem sie festlegen, was als ein korrekter Übergang von einem Satz zu einem anderen gilt und was nicht. Materiale Inferenzregeln sind also zugleich handlungsleitend und bedeutungskonstituierend.

Die gesamte Erklärungslast für die hier anvisierte Bedeutungstheorie liegt damit auf materialen Inferenzen. Mit Hilfe formaler Inferenzen lässt sich nicht zeigen, wie sich Bedeutung aus inferentiellen Zusammenhängen ergibt. Denn sie sind in semantischer Hinsicht neutral und in normativer Hinsicht letztlich wirkungslos. Für die Gültigkeit formaler Schlüsse sind nicht Regeln, sondern lediglich formale Muster im Sinne von Gegenstandsnormen verantwortlich. Das, was wir als formal-logische Regeln, Gesetze oder Prinzipien bezeichnen, hat in Wirklichkeit keine normative oder handlungsleitende Kraft. Wollen wir jedoch erklären, dass der inferentielle Zusammenhang einer Aussage bedeutungskonstitutiv ist, dann müssen wir zeigen, dass er tatsächlich normativ signifikant ist. Wir müssen zeigen, wie es in semantischer Hinsicht zur Unterscheidung von korrekt und inkorrekt kommt. Echte, normative Regeln sind unabdingbar. Mit dem Begriff der materialen Inferenz muss es daher gelingen, Schlussfolgern als eine Art Regelfolgen verständlich zu machen.

\subsection{Inferenzregeln werden implizit befolgt}

Viel war nun die Rede von materialen Inferenzregeln. Wenig wurde aber dazu gesagt, wie diese konkret aussehen. Der Leser mag daher fordern: Nun zeige mir einmal eine Regel, die jemand befolgt, wenn er 
eine sinnvolle und bedeutsame Aussage macht! Gib mir ein konkretes Beispiel für eine genuin normative Inferenzregel! Der Verzicht auf Beispiele erklärt sich jedoch dadurch, dass Regeln dieser Art einfach nicht offen zutage treten. Materiale Inferenzen zeichnen sich gerade dadurch aus, dass keine formalen Merkmale sie als solche ausweisen. Ebenso wenig ergibt sich ihre Korrektheit aufgrund formaler Kriterien. Daher darf man auch nicht erwarten, dass die entsprechenden Regeln in expliziten Formulierungen vorliegen. Wir verfügen über sie nicht wie über ein Verzeichnis von Spielregeln, das beim Regelfolgen selbst nicht präsent ist, bei Bedarf aber jederzeit zu Rate gezogen werden kann. Stattdessen ist davon auszugehen, dass es sich bei materialen Inferenzregeln um implizite Regeln handelt. Sie sind ein integrativer Bestandteil der diskursiven Praxis, die in ihrer Grundform eine Praxis des Schlussfolgerns ist, eine Praxis des Gebens und Verlangens von Gründen. ${ }^{248}$

Wer hier nach konkreten Beispielen fragt, könnte aber etwas ganz anderes im Sinn haben. Seine Forderung könnte daher rühren, dass er sich durchaus vorstellen kann, wie Inferenzregeln explizit gemacht werden können. Er würde dies in etwa wie folgt beschreiben: Dass sich keine expliziten Beispiele angeben lassen, liegt daran, dass materiale Inferenzen unvollständig sind. Sie sind, was man traditionell auch als Enthymeme bezeichnet. ${ }^{249}$ Es sind Inferenzen, in denen ein Teilschritt unterdrückt wird und unausgesprochen bleibt. Demnach muss die vollständige Formulierung einer materialen Inferenz wie „Es blitzt. Bald wird Donner zu hören sein.“ beispielsweise lauten:

Wenn es blitzt, dann wird bald Donner zu hören sein.

Es blitzt.

$\therefore$ Also wird bald Donner zu hören sein.

${ }^{248}$ Vgl. erneut Sellars (1963a), $168 \mathrm{f}$.

${ }^{249} \mathrm{Zu}$ der Auffassung, dass Enthymeme weiter verbreitet sind als explizit formale Schlussfolgerungen, vgl. Arnauld/Nicole (1965), 226. A. Arnauld und P. Nicole behaupten, die Unvollständigkeit derartiger Schlüsse schmeichle den Zuhörern und mache das Gespräch lebhafter. Zur Auffassung, dass alltägliche Schlussfolgerungen größtenteils enthymatisch sind, vgl. auch Keynes (1887), 249. Nach Sellars ist diese Sichtweise unter den (logischen) Empiristen weit verbreitet. Vgl. Sellars (1953), 313. 
Demzufolge lassen sich Inferenzregeln dadurch aufzeigen, dass die jeweiligen Inferenzen auf ihre vollständige Form zurückgeführt werden. Vollständig formuliert stellen sich dann auch materiale Inferenzregeln als formale heraus. Was in ihnen implizit ist, liegt in ihrem formalen Pedant explizit vor. Inferenzregeln lassen sich also grundsätzlich dadurch explizit machen, dass sie als formale Inferenzregeln aus- oder reformuliert werden. Dies ist die Position des (inferentialistischen) Formalisten.

Würde eine solche Erklärung zutreffen, so hätte das tiefgreifende Konsequenzen. Einerseits ginge die Eigenständigkeit materialer Inferenzen komplett verloren. Die einzige originäre Form wäre die formaler Inferenzen, aus der sie sich bestenfalls ableiten ließen. Damit gingen materiale Inferenzen allerdings für die Erklärung und Bestimmung von Bedeutung verloren. Bedeutung ließe sich nicht mehr aus dem regelgeleiteten Sprachgebrauch selbst heraus erklären. Vielmehr müsste sie aus dem Abgleich mit formal-logischen Mustern oder Schemata heraus begriffen werden. Damit würden wir wieder bei einer repräsentationalistischen Theorie der Bedeutung mit all den erwähnten Problemen enden. Das eigentliche Erklärungsziel wäre also verfehlt. Andererseits wären die Bemühungen der letzten Abschnitte, die in Zweifel geratene Normativität von Inferenzregeln wiederherzustellen, nutzlos gewesen. Denn für formale Inferenzen bleibt das Normativitätsproblem ungelöst. Wären alle Inferenzregeln letztlich formale, dann gäbe es berechtigte Zweifel, ob es sich überhaupt um genuin normative Regeln handelt.

Eine inferentielle Semantik ist auf einen eigenständigen Begriff der materialen Inferenz angewiesen. Sollen die bisherigen Überlegungen nicht hoffnungslos fehlgeleitet gewesen sein, müssen wir die reduktionistische Erklärung des Formalisten zurückweisen. Um dies mit Gewissheit tun zu können, müssen wir sie einer kritischen Untersuchung unterziehen. Dabei gilt es einerseits, die Eigenständigkeit materialer Inferenzen zu verteidigen und sie als echte Fälle des Befolgens von Schlussregeln zu etablieren. Andererseits muss sich zeigen lassen, dass materiale Inferenzregeln irreduzibel und für eine inferentielle Semantik tatsächlich unverzichtbar sind. Für die erste Aufgabe werde ich einen Gedanken aufgreifen, der auf Lewis Carroll zurückgeht. Danach können implizite Schlussregeln nur um den Preis des bekannten Regelregresses explizit gemacht werden, soll 
damit zugleich ihre Wirksamkeit dargestellt werden. Schlussregeln werden also prinzipiell implizit befolgt. Für die zweite Aufgabe werde ich auf Überlegungen Sellars' zurückgreifen. Von ihm lässt sich lernen, dass es Fälle von materialen Inferenzen gibt, die sich nachweislich nicht auf formale Regeln zurückführen lassen. Daher muss die Vorstellung, materiale Inferenzen seien nichts anderes als unvollständige formale Inferenzen, zurückgewiesen werden.

\subsection{Die Eigenständigkeit materialer Inferenzen}

Der Formalist ist der Auffassung, dass alle Inferenzen letztlich formale Inferenzen sind. Bekanntlich verfügt aber nur ein kleiner Teil aller Diskursteilnehmer über das logische Vokabular, in dem sich Inferenzregeln ausdrücklich formulieren lassen. Schlussfolgerungen nach der Art des erwähnten Schlusses von Blitz auf Donner sind jedoch vollkommen üblich. Auch dabei auftretende Inkorrektheiten werden für gewöhnlich bemerkt und korrigiert. Zumeist wird dabei jedoch nicht explizit auf Schlussregeln Bezug genommen. Wenn jemand einen Schluss zieht, dann wendet er keineswegs immer ausdrücklich eine formale Schlussregel an.

Dass Schlussregeln im Alltag häufig nicht sichtbar sind, erklärt der Formalist dadurch, dass die entsprechenden Schlüsse unvollständig sind. Diese Unvollständigkeit und das formal-logische Unvermögen vieler Diskursteilnehmer ist demnach kein Beweis dafür, dass wir letztlich nicht doch gemäß formalen Schlussregeln folgern. Schließlich sind wir uns auch vieler physikalischer Zusammenhänge bewusst, ohne die entsprechenden physikalischen Gesetze benennen und formulieren zu können. Dennoch stimmen wir dem Physiker zu, wenn er sie uns nennt. So wie er mit Hilfe von Naturgesetzen erklärt, warum sich ein bestimmter Vorgang auf eine bestimmte Weise vollzieht, so erklärt der Logiker mit Hilfe logischer Regel, warum ein bestimmter Schluss gültig ist oder nicht. Dass wir also die jeweiligen formalen Schlussregeln nicht explizit erwähnen, heißt nicht, dass wir dies im Prinzip nicht könnten. Daher behauptet der Formalist, dass erst dann ersichtlich wird, warum es sich bei einem gegebenen Schluss um einen gültigen handelt, wenn die entsprechende Schlussregel explizit hinzugefügt wird. 
Dass dies nicht ganz richtig ist, lässt sich Carrolls Aufsatz „What the Tortoise said to Achilles“ entnehmen. ${ }^{250}$ Mit dem darin formulierten Regressargument widerlegt er die Annahme, dass sich das Schlussfolgern immer an formalen Regeln orientiert und Schlüsse zur Überprüfung lediglich in die entsprechende Form gebracht werden müssen. Carroll argumentiert damit indirekt dafür, dass Inferenzregeln prinzipiell implizit befolgt werden. Demnach lässt sich an dem Schluss selbst überhaupt nicht ablesen, nach welcher Art von Inferenzregel gefolgert wird. Der Versuch, eine Regel explizit in den Vorgang des Schlussfolgerns zu integrieren, hilft nicht, den fraglichen Schluss zu erklären oder seine Gültigkeit zum Ausdruck zu bringen. Stattdessen führt er unweigerlich in einen Regress. Von daher ist das explizite Formulieren von Regeln beim Schlussfolgern selbst nicht nur unnötig, sondern sogar unmöglich.

Carroll zeigt am Beispiel des Modus Ponens, dass eine Schlussregel vor der expliziten Formulierung zuerst einmal als eine solche anerkannt und befolgt werden muss. Andernfalls kommt es nie zu einer Konklusion. Der Modus Ponens ist hier mit Bedacht gewählt. Als Schlussregel repräsentiert er den Vorgang des Schlussfolgerns schlechthin. ${ }^{251}$ Er steht stellvertretend für alle anderen Fälle formaler Schlussregeln. Sein besonderes Merkmal ist das in ihm enthaltene Konditional. Dies lässt sich als der allgemeine, satzförmige Ausdruck einer inferentiellen Beziehung bezeichnen. Der Modus Ponens besagt nun bekanntlich, dass das Konsequenz eines Konditionals abgetrennt werden darf, sofern das Antezedens wahr ist. Damit bringt er eine Art Metaregel für formal gültige Schlüsse zum Ausdruck, wonach eine Konklusion dann wahr ist, wenn die Prämissen wahr sind. ${ }^{252}$

Der Formalist behauptet nun, dass sich jede Inferenz - auch eine materiale - dadurch als gültig ausweisen lässt, dass die entsprechende Schlussregel explizit formuliert wird. Demnach muss ein gegebener Schluss lediglich in die Form eines Modus Ponens gebracht werden, um den Übergang zur Konklusion zu lizenzieren. Konkret heißt das, dass zu den Prämissen ein entsprechendes Konditional hinzugefügt wird. Dies

${ }^{250}$ Vgl. Carroll (1895).

${ }^{251}$ Vgl. Whitehead/Russell (1984), 18. Russell und Whitehead führen den Begriff der Inferenz bzw. des Schlusses mit Hilfe des Modus Ponens ein.

${ }^{252}$ Vgl. hierzu erneut Anm. 233. 
verbirgt sich auch hinter dem erwähnten Vorschlag einer formal-logischen Rekonstruktion eines materialen Schlusses von Blitz auf Donner. Der Prämisse „Es blitzt.“ und der Konklusion „Bald wird Donner zu hören sein.“ wird das Konditional „Wenn es blitzt, dann wird bald Donner zu hören sein." vorangestellt. Dadurch, so die Annahme, ist mit formalen Mitteln explizit gemacht, dass der Schluss gültig ist.

Genau dies aber enthüllt Carroll als eine absurde Vorstellung. In seinem Aufsatz konfrontiert die Schildkröte Achilles mit den folgenden drei Sätzen:

(A) Dinge, die demselben gleich sind, sind einander gleich.

$(B)$ Die beiden Seiten dieses Dreiecks sind demselben gleich.

$(Z)$ Die beiden Seiten dieses Dreiecks sind einander gleichen. ${ }^{253}$

Dass $Z$ ganz offensichtlich aus $A$ und $B$ logisch folgt, bestätigt Achilles der Schildkröte ohne Umschweife. Die Frage ist aber, warum dies so ist. Formal gesehen ist dies genau dann der Fall, wenn $A$ und $B$ wahr sind. Die Gültigkeit des Schlusses von $A$ und $B$ auf $Z$ lässt sich also auch als ein als wahr anerkanntes Konditional ausdrücken. Wer diese drei Sätze als einen gültigen Schluss identifiziert, akzeptiert dann zugleich auch den folgenden Satz:

(C) Wenn $A$ und $B$ wahr sind, muss $Z$ wahr sein. ${ }^{254}$

Damit lässt sich das, was die Schildkröte Achilles sagt, folgendermaßen zusammenfassen:

$A$ und $B$ sind wahr.

Wenn $A$ und $B$ wahr sind, dann muss $Z$ war sein.

$\therefore$ Also muss $Z$ wahr sein.

Und dies ist ganz offensichtlich eine Anwendung des Modus Ponens.

Geht man der Sache derart auf den Grund, so kommt man zu dem Ergebnis, dass jemand den Schluss von $A$ und $B$ auf $Z$ letztlich genau

${ }^{253}$ Vgl. Carroll (1895), 278. (Diese und die folgenden sind meine Übersetzungen, A. S.)

${ }^{254}$ Vgl. ebd., 279. 
deswegen für logisch zwingend hält, weil ihn der Modus Ponens dazu veranlasst. Die spontane Zustimmung lässt sich durch das unterdrückte Konditional $(C)$ erklären. Sollte jemand dies auf Anhieb nicht so sehen, sollte er also $Z$ nicht als logische Konsequenz von $A$ und $B$ anerkennen, dann genügt es, ihm dies ausdrücklich vor Augen zu führen. Die Idee ist also die, den Prämissen $A$ und $B$ das Konditional $C$ als zusätzliche Prämisse hinzuzufügen. Damit soll explizit gemacht werden, dass und inwiefern der Schluss einer formalen Inferenzregel, nämlich dem Modus Ponens folgt.

Carrols Aufsatz macht aber deutlich, dass genau dies nicht möglich ist. Die Schildkröte ist zwar von der Richtigkeit von $A$ und $B$ überzeugt. Auch dem Vorschlag, $C$ als zusätzlich Prämisse explizit in den Schluss aufzunehmen, stimmt sie zu. Dass dadurch ein gültiger Schluss entsteht, dass also $Z$ nun aus $A, B$ und $C$ (logisch) folgt, will sie nicht akzeptieren. Denn dies müsste durch ein weiteres Konditional gezeigt werden. Tatsächlich bietet Achilles auch an, ein solches zu den Prämissen hinzuzufügen:

(D) Wenn $A$ und $B$ und $C$ wahr sind, muss $Z$ wahr sein. ${ }^{255}$

Doch auch das ändert nichts an der bisherigen Situation. Stattdessen ist längst ein unendlicher Regress in Gang.

Vom Standpunkt des Formalisten ist es das Konditional, das den Modus Ponens (MP) explizit macht und dem Schluss letztlich seine Gültigkeit verleiht. Auch wenn in einem Zwischenschritt die Regel der universellen Instantiierung (UI) berücksichtigt wird, kommt dieser letztlich zur Anwendung. Das zeigt die folgende Schematisierung:
(A') $\forall x(F(x) \rightarrow G(x))$
[Annahme]
$\left(B^{\prime}\right) F(t)$
[Annahme]
(C') $F(t) \rightarrow G(t)$
[UI aus $\left.\left(A^{\prime}\right)\right]$
(Z') $G(t)$
[MP aus $\left.\left(B^{\prime}\right),\left(C^{\prime}\right)\right]$

Carroll macht aber deutlich, dass wir den Schluss bereits gezogen haben, bevor wir diese explizite Regel konsultiert haben. Darüber sind sich die

${ }^{255}$ Vgl. ebd. 
Protagonisten seines Stücks eigentlich auch von Anfang an einig. Das Gedankenexperiment, in dem sich die Schildkröte als logische Skeptikerin zu erkennen gibt, untermauert dies nur noch einmal. Sobald die Prämissen als wahr akzeptiert sind, ist der Schluss auf die Konklusion legitimiert. Es ist nicht einzusehen, warum er durch ausdrückliches Hinzufügen des Konditionals seine Notwendigkeit erhalten soll, wenn er diese zuvor nicht auch schon besaß. Eine Ergänzung der Prämissen um das enthymatisch unterdrückte Konditional führt in Wirklichkeit nur $\mathrm{zu}$ einer endlosen Vervielfältigung der Prämissen, ohne dass sich an der Gültigkeit des Schlusses etwas ändert. Es führt zwar dazu, dass die Regel in Erscheinung tritt und in theoretischer Hinsicht akzeptiert werden kann, nicht aber dazu, dass sie auch tatsächlich praktisch zur Anwendung kommt. ${ }^{256}$

Es muss ein implizites Befolgen von Inferenzregeln unabhängig von ihrer expliziten Formulierung geben. Eine explizit formulierte Inferenzregel ist nichts, was selbst unmittelbarer Anteil am Vorgang des Schlussfolgerns hat. Selbst wenn sich im Nachhinein eine unterdrückte Prämisse findet, darf diese nicht mit der Regel selbst verwechselt werden. Das gilt auch dann, wenn sie die Form eines Konditionals hat. Inferenzregeln dürfen weder als Prämissen noch als Konditionale behandelt werden. ${ }^{257}$ Wird diese Unterscheidung nicht eingehalten, so droht ein Regress. Auch in formalen Inferenzen werden die Regeln stets implizit befolgt. Die Praxis des Schlussfolgerns ist kein explizites Anerkennen propositional formulierter Schlussregeln. Die Möglichkeit, eine materiale Inferenz nachträglich durch eine Prämisse zu ergänzen, erlaubt keinen Rückschluss darauf, dass die dabei befolgte Regel in Wirklichkeit eine formale war. Alles, was wir wissen, ist, dass der Schluss implizit bereits vollzogen wurde. Formale Inferenzregeln können eine (nachträgliche) Erklärung sein. Die Möglichkeit impliziter materialer Inferenzregeln bleibt davon aber unbeeinträchtigt. Die Eigenständigkeit materialer Inferenzen wird durch eine formalistische Erklärung weder eingeschränkt noch aufgehoben.

${ }^{256}$ Vgl. Ryle (1945/46), 6.

${ }^{257}$ Dies ist auch Carrolls eigene Diagnose zu seinem Aufsatz. Vgl. Dodgson (1977), 472. $\mathrm{Zu}$ einem Überblick über weitere Lesarten der Geschichte vgl. Engel (2004). 
Carrolls Regress des Konditionals macht also deutlich, dass sich inferentielle Zusammenhänge nicht vollständig explizit machen lassen. Jedenfalls sind explizit formulierte Inferenzregeln nicht das, was solche Zusammenhänge herstellt. Weder müssen, noch können wir einer unabhängigen Aussage einfach eine Regel wie den Modus Ponens oder die universelle Instantiierung anhängen, um ihn zu erzeugen. Ebenso wenig ist er auf eine nachträgliche Entdeckung angewiesen. Die Aussagen müssen bereits in einem inferentiellen oder logischen Zusammenhang zueinander stehen, wenn die Regel diesen Übergang explizit machen soll. Explizit formulierte Inferenzregeln bringen also lediglich zum Ausdruck, dass Sätze oder Aussagen bereits inferentiell in Zusammenhang stehen. Diese Einsicht entspricht der These von der grundsätzlichen inferentiellen Gliederung des sinnvollen und rationalen Diskurses.

Eine angemessene Reaktion auf die Behauptung des Formalisten besteht daher in der Umkehrung der Erklärungsreihenfolge. Nicht formale Inferenzregeln erklären, wie es zu korrekten Inferenzen kommt. Korrekte Inferenzen erklären formale Regeln. Formale Inferenzregeln lassen sich auf der Grundlage von materialen Inferenzregeln erklären, welche implizit in der Praxis des Schlussfolgerns befolgt werden. ${ }^{258}$ Sätze oder Aussagen stehen aufgrund ihrer semantischen Gehalte in Zusammenhang. Unsere diskursive Praxis ist geprägt von der Erzeugung und Beurteilung dieser Zusammenhänge. Dabei verfügen wir immer schon über Kriterien, um diese Übergänge von einem Satz $\mathrm{zu}$ einem anderen als korrekt oder inkorrekt $\mathrm{zu}$ beurteilen. Die Korrektheitsbedingungen für inferentielle Zusammenhänge sind in Form von materialen Inferenzregeln immer schon implizit in der diskursiven Praxis enthalten. Dies lässt sich gegebenenfalls im Nachhinein mit Hilfe von formalen Inferenzregeln explizit machen. Formale Inferenzregeln haben somit eine expressive Funktion. Sie stellen inferentielle Zusammenhänge explizit als solche dar. In den folgenden Abschnitten werde ich nicht nur bestätigen, dass materiale Inferenzregeln eine eigenständige Klasse von Schlussregeln bilden. Ich werde auch zeigen, inwiefern dies im Rahmen einer inferentiellen Semantik von zentraler Bedeutung ist.

${ }^{258}$ Wie dies im Einzelnen funktioniert, erkläre ich in Kap. 5.15. 


\subsection{Die wesentliche Rolle materialer Inferenzen}

Das Erklärungsmodell des Formalisten ist überaus komplex und voraussetzungsreich. Selbst eine einfache sprachliche Performanz wie das Schließen von Blitz auf Donner oder von Regen auf nasse Straßen gilt als unvollständig und muss durch zusätzliche Annahmen ergänzt werden. Was wir „wirklich“ tun, wenn wir im Alltag von einem Satz auf einen anderen schließen, müssen wir uns permanent von einem formal-logischen Subtext begleitet vorstellen. Um daher die verborgenen Funktionsweisen enthymatisch verkürzter Schlüsse zu entschlüsseln, muss die formalistische Erklärung in letzter Konsequenz auf einen angeborenen logischen Grundbestand zurückgreifen. Die einzige Alternative wäre, Inferenzregeln ganz aus sich selbst heraus zu erklären. Diese aber würde zwangsläufig in einen explanatorischen Zirkel führen, würden nicht doch einige logische Begriffe oder Regeln als angeboren und nicht weiter erklärbar vorausgesetzt. Der Formalist muss also davon ausgehen, dass wir bereits mit einem formal-logischen Grundvokabular ausgestattet auf die Welt kommen. Es müsste jedoch einiges dazu gesagt werden, wie man sich Bestand und Umfang eines solchen Vokabulars vorzustellen hat.

Eine Erklärung in der umgekehrten Reihenfolge betrachtet formallogisches Wissen dagegen als aus einfachen Fähigkeiten des gehaltsbasierten Schließens abgeleitet. Sie verzichtet dabei auf anspruchsvolle theoretische Vorannahmen und setzt nur die gewöhnliche, diskursive Praxis voraus, in der Aussagen als korrekt oder inkorrekt behandelt werden. Es kann daher nicht überraschen, dass eine Ableitung des Begriffs der formalen Inferenz aus dem der materialen Inferenz auf geradezu „natürliche Weise“ möglich ist, während dies für die umgekehrte Richtung nicht gilt. ${ }^{259}$ Denn die Korrektheit formaler Inferenzen lässt sich einfach dadurch bestimmen, dass diese in materialer Hinsicht korrekt sein müssen und durch das Ersetzen nicht-logischer Ausdrücke in den Prämissen und Konklusionen nicht inkorrekt werden dürfen. Ist also der Begriff der materialen Inferenz gegeben, so kann man die Klasse der formal gültigen Inferenzen als die Klasse derjenigen Inferenzen einführen, die bei der Ersetzung beliebiger nicht-logischer Ausdrücke material gültig bleiben.

${ }^{259}$ Vgl. Brandom (1994), 104 f. 
Eine entsprechende Einführung der Klasse material gültiger Inferenzen ist dagegen nicht möglich. Es gibt kein vergleichbar einfaches und offensichtliches Kriterium formaler Inferenzen, das zur Bestimmung materialer Inferenzen dienen kann.

Dass sich formale Inferenzen nach dem Prinzip der Ersetzbarkeit aus materialen Inferenzen ableiten lassen, gibt einen Hinweis darauf, dass letztere die Erklärungsleistung ersterer übertreffen. Aber so wenig eine Anzahl von Fahrzeugen, die in dieselbe Richtung fahren, beweist, dass sie in einer Einbahnstraße fahren, so wenig beweist diese „natürliche Ableitbarkeit" in eine Richtung bereits die einzigartige und unersetzbare Stellung materialer gegenüber formaler Inferenzen. Dazu braucht es stärkerer Gründe. Es müsste sich nachweisen lassen, dass eine Ableitung in die entgegengesetzte Richtung tatsächlich unmöglich ist. Um zu zeigen, warum materiale Inferenzen für Bedeutung wesentlich und unverzichtbar sind, müsste sich ein sprachliches Phänomen finden lassen, das sich nicht auf formale Prinzipien zurückführen lässt. Benötigt würde eine Art Folgebeziehung, die tatsächlich nur als Funktion materialer Inferenzregeln $\mathrm{zu}$ verstehen ist.

Als ein solches Phänomen hat Sellars irreale Bedingungs- oder Konditionalsätze ausgewiesen. ${ }^{260}$ Dies sind Sätze wie „Wenn ich dieses Stück Kreide losgelassen hätte, wäre es gefallen.“ oder „Wenn es einen Blitz gäbe, dann gäbe es Donner." In ihnen werden Sachverhalte beschrieben, die möglich oder wahrscheinlich sind, die aber nur in Gedanken konstruiert werden. Haupt- und Nebensatz eines irrealen Bedingungssatzes bilden zusammen ein Konditionalgefüge. Es kommt eine Folgebeziehung zum Ausdruck, die aber nicht mehr als ein Gedankenspiel ist. Irreale Bedingungssätze mögen daher als eine recht spezielle Klasse von Inferenzen erscheinen. Sie spielen aber eine unverzichtbare Rolle in natürlichen Sprachen, sei es in der Wissenschaft oder im alltäglichen Leben. Sätze wie der über das Loslassen von Kreide begegnen uns immer wieder.

${ }^{260} \mathrm{Vgl}$. auch für das Folgende Sellars (1953), insbes. $323 \mathrm{ff}$. 
Prinzipiell lassen sich auch irreale Bedingungssätze in formale und materiale unterscheiden. ${ }^{261}$ Insofern lassen sich auch entsprechende formale und materiale Inferenzregeln zuordnen. So bringt der Satz:

(16) Wenn dies rot und quadratisch wäre, dann wäre es rot.

offenkundig dieselbe formale Inferenzregel zum Ausdruck wie der Schluss von „Dies ist rot und quadratisch“ auf „Dies ist rot". Analog dazu können wir sagen, dass der Satz:

(17) Wenn es einen Blitz gäbe, dann gäbe es Donner.

dieselbe materiale Inferenzregel ausdrückt wie der Schluss von „Es gibt einen Blitz.“ auf „Es gibt Donner.“ Es gilt jedoch zu klären, ob sich auf irreale Bedingungssätze das gleiche formalistische Erklärungsmodell anwenden lässt wie auf indikativische Sätze. Lassen auch sie sich als unvollständige, enthymatisch verkürzte formale Inferenzen verstehen?

Der Formalist behauptet, dass auch irreale Bedingungssätze ihre inferentielle Kraft grundsätzlich rein formalen Prinzipien verdanken. Er ist davon überzeugt, dass eine vollständige, explizite Ausformulierung dieser Konditionalgefüge dies verdeutlichen kann. Ich werde im Folgenden vier mögliche Kandidaten für eine zusätzliche, unterdrückte Prämisse diskutieren. $^{262}$ Wie sich nach einer eingehenden Untersuchung herausstellen wird, sind sie aber letztlich allesamt ungeeignet, materiale irreale Bedingungssätze formal-logisch zu rekonstruieren. Nehmen wir zunächst einmal an, ein solcher Satz würde, entsprechend der oben vom Formalisten vorgeschlagenen Vorgehensweise, um die folgende allgemeine Aussage ergänzt:

(18) Da es immer dann, wenn es einen Blitz gibt, auch Donner gibt, würde es Donner geben, wenn es einen Blitz gäbe.

${ }^{261}$ Vgl. ebd., 323.

${ }^{262} \mathrm{Vgl}$. auch für das Folgende ebd., $324 \mathrm{f}$. 
Man könnte annehmen, bei dem so gewonnen Satz handle es sich um einen speziellen Fall der universellen Instantiierung. ${ }^{263}$ Es hängt dabei aber einiges davon $a b$, wie die einleitende, allgemeine Aussage interpretiert wird. Wird sie als ein Tatsachenbericht verstanden und als materiale Implikation interpretiert, so kann die daraus abgeleitete Instantiierung kein irrealer Bedingungssatz sein. Letzterer würde ja gerade keinen (realen) Tatsachenbericht, sondern vielmehr ein (irreales) Gedankenspiel zum Ausdruck bringen.

Materiale Implikationen und irreale Bedingungssätze unterscheiden sich hinsichtlich ihres Wahrheitswertverlaufes. Der Wahrheitswert materialer Implikationen hängt ausschließlich vom Wahrheitswert seiner Komponenten (Antezedens und Konsequenz) ab. Der Wahrheitswert irrealer Bedingungssätze ist dagegen situationsbezogen. So kann es Situationen geben, in denen die Wahrheitswerte der Komponenten übereinstimmen, während sich der Wahrheitswert der entsprechenden Konditionalgefüge unterscheidet. Wenn sich beispielsweise Hannah in Deutschland aufhält, dann haben die folgenden beiden Konditionalsätze sowohl ein falsches Antezedens als auch ein falsches Konsequens:

(19) Wenn Hannah sich in New York aufhielte, dann würde sie sich in Nordamerika aufhalten.

(20) Wenn Hannah sich in New York aufhielte, dann würde sie sich in Asien aufhalten.

Allerdings ist (19) wahr, während (20) offensichtlich falsch ist. Diese Unterscheidung ist bei der materialen Implikation nicht möglich. Wann immer das Antezedens falsch ist, ist auch das Konditionalgefüge wahr. ${ }^{264}$ Aufgrund des modalen Unterschieds der beiden Satzteile in (18) kann also gar nicht von einer korrekten Anwendung der universellen Instantiierung gesprochen werden.

263 Aus , $B x$ impliziert $D x^{\prime}$ wird , $B a$ impliziert $D a$ ' abgeleitet. Dies ist eine spezielle Anwendung der Ableitung von $F(a)$ aus $\forall x F(x)$. Vgl. ebd., 324. Wenn ich im Folgenden von universeller Instantiierung rede, ist dieser Spezialfall gemeint.

264 Vgl. auch Goodman (1947). E. Adams schlägt vor, insbesondere im Zusammenhang von irrealen Bedingungssätzen von Rechtfertigung oder Unterstützung anstatt von Wahrheit zu sprechen. Vgl. Adams (1970). 
Um dies zu ermöglichen, müsste auch die sich aus der allgemeinen Aussage ableitende Konditionalaussage als Ausdruck einer materialen Implikation interpretiert werden. Soll der Satz daher tatsächlich eine Anwendung der universellen Instantiierung sein, so muss er lauten:

(21) Da es (den Tatsachen entsprechend) immer dann, wenn es einen Blitz gibt, auch Donner gibt, wird es Donner geben, wenn es einen Blitz geben wird.

Damit aber ist der irreale Modus aus dem Satz verschwunden. Nun liegt zwar eine gültige universelle Instantiierung vor. Eine Erklärung von (17) mittels Ergänzung zu einer formalen Inferenz ist dies allerdings nicht mehr. Mit dem ursprünglichen irrealen Bedingungssatz hat die so gewonnene Konditionalaussage nicht mehr viel gemein.

Aber nicht nur die Dimension des Irrealen geht auf diesem Weg verloren. Mit der Interpretation des Konditionalgefüges als materiale Implikation büßt der irreale Bedingungssatz auch seinen Status als Schlussfolgerung ein. Denn streng genommen ist eine materiale Implikation kein Schluss, sondern lediglich die Behauptung eines wahrheitsfunktionalen Zusammenhangs. Deshalb ist ein Satz wie „Wenn die Venus ein Planet ist, dann besteht Luft aus Sauerstoff.“ zwar eine (wahre) materiale Implikation, aber keinesfalls eine (materiale) Inferenz. Wollten wir durch universelle Instantiierung tatsächlich eine Folgebeziehung gewinnen, so müssten wir die allgemeine Aussage anders interpretieren. Wir müssten auch sie so verstehen, dass sie eine Beziehung dieser Art ausdrückt. Der gesuchte Satz müsste also folgendermaßen lauten:

(22) Da es (im Sinne einer Folgebeziehung) immer dann, wenn es einen Blitz gibt, auch Donner gibt, folgt aus dem Umstand, dass es einen Blitz geben wird, dass es Donner geben wird.

Damit wäre, was die inferentielle Kraft anbelangt, ein Äquivalent zu dem irrealen Bedingungssatz in (18) gefunden. Allerdings wird nun bereits in der allgemeinen Konditionalaussage eine materiale Inferenzregel eingeführt. Nur deshalb lässt sich daraus eine Folgebeziehung ableiten, die mit (17) vergleichbar ist. Das ist der negative Effekt dieser Interpretation. 
Das Ziel, den ursprünglichen irrealen Bedingungssatz mittels formaler und ohne Rückgriff auf materiale Inferenzregeln zu erklären, ist damit verfehlt.

Bisher sind also alle Versuche, (17) als die verkürzte Form einer formalen Inferenz auszuweisen, gescheitert. Die Schwierigkeit ist, den Aspekt des Irrealen zu bewahren, ohne jedoch den Status als Inferenz aufzugeben oder bereits von Anfang an mit materialen Inferenzregeln zu operieren. Hier ist ein letzter Vorschlag für eine explizit formale Interpretation des fraglichen irrealen Bedingungssatzes:

(23) Wenn es gleichermaßen der Fall wäre, dass es immer dann, wenn es einen Blitz gibt, Donner gibt, und dass es einen Blitz gibt, dann würde es Donner geben.

Dieser Vorschlag enthält eine etwas anders geartete formale Regel, als die bisher verwendete universelle Instantiierung. ${ }^{265}$ Zudem kommt (17) in dieser Version nicht schon in der allgemeinen Konditionalaussage vor. Es könnte sich also durchaus um die gesuchte formale Inferenz handeln.

Allerdings führt auch diese Interpretation nicht zu dem gewünschten Ergebnis. Denn bei genauem Hinsehen liefert sie kein gültiges Äquivalent $\mathrm{zu}$ (17). Das Problem ist, dass eine auf diese Weise abgeleitete Konditionalaussage niemals falsch sein kann. Gemäß dieser Interpretation wäre ein materialer irrealer Bedingungssatz letztlich immer ein wahrer Satz. Denn die formale Regel, die im Antezedens formuliert wird, führt immer zu einem wahren Konsequenz. Dafür sorgt das darin enthaltene „immer dann“. Unbestritten gibt es aber auch irreale Bedingungssätze mit einem falschen Konsequenz. Der Satz „Wenn ich im Lotto gewinnen würde, würde ich eine Weltreise machen." beispielsweise beinhaltet prinzipiell auch die Möglichkeit, dass ich keine Weltreise mache. Das genau ist ja der Sinn des irrealen Modus. Diese Option besteht in (23) jedoch nicht mehr.

Keiner der genannten Vorschläge vermag materiale irreale Bedingungssätze mit Hilfe formaler Inferenzregeln zu erklären. Die dabei angewandten Regeln müssen also materiale Inferenzregeln sein. Der Formalist könnte dem zwar entgegensetzen, dass irreale Bedingungssätze ein entbehrliches sprachliches Element sind. Denn prinzipiell ist es

${ }^{265}$ Aus , $(B x$ impliziert $D x)$ und $B a$ ' wird , $D a$ ' abgeleitet. 
natürlich möglich, eine Sprache zu konstruieren, die auf sie verzichtet und dabei dennoch extensional bleibt. Es sind aber nicht diese Sätze selbst, die unentbehrlich sind. Es ist die Funktion, die sie in der Sprache erfüllen. ${ }^{266}$ Und die liegt eben darin, einen Schluss wie den von Blitz auf Donner auch im Modus des Irrealen $\mathrm{zu}$ autorisieren. Stünden materiale irreale Bedingungssätze in der Objektsprache nicht zur Verfügung, so müssten wir für diese Aufgabe auf ein anderes Vokabular zurückgreifen. Anstatt beispielsweise zu sagen „Wenn $F$ ein $G$ wäre, dann wäre es ein $H$.“, würden wir in die Metasprache wechseln und sagen „Von , $F$ ist ein $G$ ' darf auf , $F$ ist ein $H^{\prime}$ geschlossen werden." Dadurch wäre dasselbe Ziel erreicht. Formale Inferenzen können diese Funktion jedenfalls ganz offensichtlich nicht übernehmen.

Damit ist ersichtlich, warum eine Semantik, die Bedeutung als eine Funktion inferentieller Beziehungen versteht, auf den Begriff der materialen Inferenz angewiesen ist. Denn dies ist nicht nur genau die Art Inferenz, für die semantischer Gehalt relevant ist. Es ist auch die, die im Modus des Irrealen erwiesenermaßen unverzichtbar ist. Materiale irreale Bedingungssätze bilden einen wichtigen Teilbereich der Sprache, der für die Konstitution von Bedeutung durchaus relevant ist. Schon die Behauptung, dass materiale Inferenzregeln nur dann eine Unterscheidung in korrekt und inkorrekt erlauben, wenn sie in explizite Regelformulierungen überführt werden, ist unhaltbar. Denn hier droht ein infiniter Regress. Inferenzregeln verrichten ihre Arbeit primär implizit. Die Vorstellung, es handle sich bei materialen Inferenzen in Wirklichkeit um enthymatisch verkürzte formale Inferenzen, ist ebenso wenig plausibel. Denn anhand von irrealen Bedingungssätzen lässt sich zeigen, dass materiale Inferenzregeln nicht vollständig aus formalen Inferenzregeln ableitbar sind. Insofern ist der Begriff der materialen Inferenz umfassender als der der formalen. Eine Ableitung formaler Inferenzen aus materialen Inferenzen ist problemlos möglich, nicht aber das Gegenteil.

Materialen Inferenzregeln sind in Wirklichkeit implizite Regeln. Sie sind genau der Typ Regel, der für die Konstitution von Bedeutung in Frage kommt, und dies sowohl im indikativischen als auch irrealen Modus des Sprachgebrauchs. Insofern ist auch nicht von Belang, dass formale

${ }^{266}$ Vgl. Sellars (1953), 326. 
Inferenzregeln überhaupt keine normative oder handlungsleitende Kraft haben. Für eine inferentielle Semantik, die auf eine normative Pragmatik aufbaut, sind sie unbedeutend. Als eine eigenständige und irreduzible Klasse können materialen Inferenzen diese Aufgabe umfassend erfüllen. Damit ist nicht gemeint, dass formale Inferenzregeln in jeder Hinsicht verzichtbar sind. Ihre expressive Funktion hat ihren eignen Wert, wenn auch nicht den, materiale Inferenzen überflüssig $\mathrm{zu}$ machen. Zwar verdanken inferentielle Übergänge oder Zusammenhänge ihr Dasein und ihre Relevanz nicht erst einer expliziten Formulierung. Eine formale Rekonstruktion kann aber durchaus einen pragmatischen Wert haben. Denn dadurch können inferentielle Zusammenhänge in der diskursiven Praxis selbst thematisiert werden. Formale Inferenzen lassen sich dazu verwenden, inferentiell verknüpfte Aussagen als solche zu markieren und als neue, zusammengesetzte Aussage für weitere Inferenzen zur Verfügung $\mathrm{zu}$ stellen. ${ }^{267}$ Auf diese Weise können Aussagen, die beispielsweise ein Konditional enthalten, wiederum zu Prämissen weiterer (materialer) Inferenzen werden. So gesehen erfüllen formale Inferenzen dank ihres expressiven Charakters eine selbstreferentielle Funktion in der Sprache. Sie fungieren als schematisches Modell der sprachlichen Praxis selbst, die im Wesentlichen eine Praxis des materialen Schließens ist. So können sie das, was wir immer schon unreflektiert tun, selbst zum Gegenstand unseres Tuns machen.

\subsection{Inferentielle Semantik und normative Pragmatik}

Dass materiale Inferenzen die Bedeutung von Aussagen konstituieren, lässt sich aus den semantischen Gegebenheiten allein nicht erklären. Eine solche Erklärung wäre zirkulär. Die bedeutungsbestimmende Funktion materialer Inferenzen ergibt sich aus der Rückbindung der inferentiellen Semantik an die normative Pragmatik. Je nachdem unter welchem Vorzeichen man Sprache analysiert, treten eher normative oder inferentielle Aspekte in den Vordergrund. Die Normativität gerät vor allem dann in den Blick, wenn man ihren Gebrauch untersucht. Die inferentielle

${ }^{267}$ Dies ist ein entscheidender Aspekt für die Erklärung subsententialer Einheiten wie singuläre Termini oder Prädikate. Vgl. Brandom (1994), 381 f. u. 402 f. Zur expressiven Funktion formaler Inferenzen vgl. auch Brandom (1994), 105 ff. 
Gliederung ist dagegen ein strukturelles Merkmal von Sprache selbst. Normativität und Inferentialität sind also zwei Seiten ein und derselben Medaille. Materiale Inferenzen sind das semantische Gegenstück zum impliziten oder „,blinden“ Regelfolgen auf Seiten der Pragmatik.

Ohne die Normativität der diskursiven Praxis ist die Relevanz und Notwendigkeit inferentieller Zusammenhänge nicht intelligibel. Daher muss Sprache nicht nur inferentiell gegliedert, sondern ihr Gebrauch auch normativ signifikant sein. Dass Sprache inferentiell gegliedert ist, heißt ja grundsätzlich nichts anderes, als dass von einer Aussage zu einer anderen übergegangen werden kann, darf oder sollte, oder dass ein solcher Übergang gerade ausgeschlossen ist. Die Verwendung einer Aussage hat also stets normative Konsequenzen, was die Auswahl der Aussagen betrifft, die daran unmittelbar angeknüpft werden dürfen oder nicht. Ausdrücke wie „können“, „,ürrfen“, „,sollen“ und „ausgeschlossen sein“ sind normatives Vokabular. Daher kann die Erklärung von materialer Inferenz und Bedeutung darauf zurückgreifen. So ergibt sich die inferentielle Gliederung aus der bereits als implizit normativ ausgewiesenen sprachlichen Praxis.

Im Wesentlichen ging es bei der Untersuchung der sprachlichen Praxis darum, dass dem Behaupten und Zuschreiben von Überzeugungen bestimmte normative Status auf Seiten der Diskursteilnehmer entsprechen. Die Terminologie, die ich in diesem Zusammenhang eingeführt habe, war die der Festlegung, der Berechtigung und der Unvereinbarkeit. Einem Sprecher kommen diese normativen Status dadurch zu, dass ein anderer eine entsprechende normative Einstellung ihm gegenüber einnimmt. Auf diese Weise wird jemand als auf eine Überzeugung festgelegt oder als zu einer Überzeugung berechtigt oder nicht berechtigt betrachtet und behandelt.

Diese Terminologie lässt sich nun wieder aufgreifen und mit Blick auf die inferentielle Gliederung von Sprache reformulieren. Von einem normativen Standpunkt aus betrachtet bedeutet das Behaupten eines Satzes die Festlegung auf eine Überzeugung. Implizit sind damit weitere Überzeugungen auf dreierlei Art verbunden: Eine Festlegung bedeutet immer auch die Festlegung auf weitere Festlegungen, die Berechtigung zu weiteren Festlegungen und die ausgeschlossene Berechtigung zu weiteren Festlegungen. Von einem inferentiellen Standpunkt aus betrachtet gilt dies 
für die Sätze, die in einem relevanten oder notwendigen Zusammenhang mit dem ursprünglichen Satz stehen oder eben gerade nicht. Dies ist der Zusammenhang der angemessenen Umstände und Folgen. Denn prinzipiell ist jeder Satz zugleich Umstand und Folge anderer Sätze. Ein solcher Zusammenhang ergibt sich dadurch, dass Sätze etwas miteinander zu tun haben, dass sie inhaltlich zusammenhängen. Somit kann man ihn als (gültige) materiale Inferenz bezeichnen.

Es besteht nun die Möglichkeit, den normativen in den inferentiellen Standpunkt zu überführen. Eine materiale Inferenz kommt dann prinzipiell dem gleich, worauf jemand durch eine Behauptung zusätzlich festgelegt ist, wozu er zusätzlich berechtigt ist oder was damit unvereinbar ist. Diese strukturellen Gegebenheiten ergeben sich daraus, wie ein Diskursteilnehmer in der Praxis von anderen betrachtet und behandelt wird. Ihr sprachliches Verhalten lässt diese Zusammenhänge zutage treten. Damit wird ersichtlich, wie die normativen Status der Festlegung, der Berechtigung und der Unvereinbarkeit materiale Inferenzen begründen und wie das wiederum zur Konstitution von Bedeutung führt. Einen Satz als die korrekte oder inkorrekte Konsequenz eines anderen $\mathrm{zu}$ behandeln, ist letztlich nichts anderes als seine inhaltliche Bestimmung. Indem Sprecher die Verwendung von Aussagen bestätigen oder verneinen, konstituieren sie ihre jeweilige Bedeutung. Anders gesagt lokalisieren sie die einzelnen Aussagen innerhalb des Geflechts inferentieller Zusammenhänge. So verstanden lässt sich also Bedeutung mit Hilfe von Inferenzen erklären, ohne diese dabei bereits selbst vorauszusetzen. Bedeutung gibt es erst und nur dann, wenn die diskursive Praxis in Gang ist.

\subsection{Drei Arten des inferentiellen Zusammenhangs}

In Analogie zu der dreigliedrigen Normativität sprachlicher Praxis lassen sich auch inferentielle Beziehungen einer dreigliedrigen Klassifikation unterziehen. ${ }^{268}$ Ein grundlegendes funktionales Merkmal gültiger Schlüsse ist dabei die Übertragung und den Erhalt normativer Status. Im selben Maße wie formale Inferenzen wahrheitswerterhaltend sind, sind materiale Inferenzen statuserhaltend. Jeder Überzeugung

${ }^{268}$ Vgl. Brandom (1994), 168 f. u. 188 f. 
entspricht im sprachlichen Umgang ein normativer Status auf Seiten desjenigen Diskursteilnehmers, der sie äußert oder zugeschrieben bekommt. Dem wiederum entspricht auf Seiten der strukturellen sprachlichen Gegebenheiten eine inferentielle Relation $\mathrm{zu}$ anderen Überzeugungen, in der dieser Status übertragen und erhalten wird.

Die Idee ist also die, Folgerungsbeziehungen hinsichtlich der dabei eingenommenen oder zugeschriebenen normativen Status zu unterscheiden. Dabei werden die unterschiedlichen Formen praxisimpliziter Normativität in entsprechende inferentielle Beziehungen übersetzt. Grundlegend sind zunächst die beiden Status der Festlegung und der Berechtigung. Korrekte Inferenzen, die diese in der Prämisse enthalten, kann man entsprechend als festlegungserhaltend und berechtigungserhaltend bezeichnen. Ich werde vereinfachend auch von Implikationen und Unterstützungen sprechen. Ist die Berechtigung $\mathrm{zu}$ einer Behauptung aufgrund der Festlegung auf eine andere ausgeschlossen, so entspricht dies der inferentiellen Beziehungen der Unvereinbarkeit. Dies sind die drei Arten von Beziehungen, aus denen sich die inferentielle Rolle und damit die Bedeutung einer Aussage zusammensetzen.

Die Beziehung der Implikation betrifft Aussagen, auf die ein Sprecher als Folge einer Festlegung zusätzlich festgelegt ist. Sie stellt für ihn eine Forderung oder Verpflichtung dar. Dabei überträgt sich der normative Status der Festlegung von der Äußerung oder Zuschreibung einer bestimmten Überzeugung auf weitere Überzeugungen. So zieht beispielsweise die Festlegung auf „Berlin liegt östlich von Hamburg.“ die Festlegung auf „Hamburg liegt westlich von Berlin.“ nach sich. Ebenso impliziert die Behauptung, dass der Mord am Mittwoch geschah, die Behauptung, dass das Opfer am Dienstag noch am Leben war. Für material gültige Inferenzen wie diese gilt, dass jemand, der auf die Prämisse festgelegt ist, gleichermaßen auf die Konklusion festgelegt ist.

Auch formal gültige Inferenzen nehmen solche festlegungserhaltenden Beziehungen in Anspruch. So impliziert beispielsweise die Behauptung „Dies ist rot und quadratisch.“ die Behauptung „Dies ist rot.“. Allerdings spielen formal-logische Deduktionen wie diesen bei der Konstitution von Bedeutung eine untergeordnete Rolle. Denn wie das Beispiel noch einmal verdeutlicht, sind sie ihrer Art nach gehaltsneutral. Abgesehen von der Funktion, inferentielle Zusammenhänge selbst in Form von 
Konditionalsätzen für weitere (materiale) Inferenzen zur Verfügung zu stellen, leisten sie hier keinen direkten Beitrag.

Die Beziehung der Unterstützung betrifft Aussagen, zu denen ein Sprecher als Folge einer Festlegung oder Berechtigung ebenfalls berechtigt ist. Sie erteilt die Erlaubnis zu weiteren Festlegungen, sofern sonst nichts dagegen spricht. Der normative Status der Berechtigung überträgt sich von der Äußerung oder Zuschreibung einer bestimmten Überzeugung auf weitere Überzeugungen. Insbesondere Induktionen beruhen auf dieser Art inferentieller Beziehung. So stützt beispielsweise die Behauptung „Draußen regnet es.“ den induktiven Schluss auf „Draußen wird die Temperatur sinken." Wer ersteres behauptet, ist auch dazu berechtigt, letzteres zu behaupten. Er ist jedoch nicht darauf festgelegt. Denn es ist damit auch vereinbar, dass es sich nur um einen kurzen Schauer handelt, der keinen Einfluss auf die Temperatur hat. Ähnlich verhält es sich beispielsweise mit der Behauptung, dass dieses Gefäß aus Glas ist. Sie gibt Grund zu der Annahme, dass es zerbrechen wird, wenn es herunterfällt. Es kann aber auch zu der Behauptung berechtigen, dass es heil bleibt, wenn es auf einen sehr weichen Untergrund fällt oder besonders gehärtet ist.

Berechtigungserhaltende Folgerungsbeziehungen kommen zwar ausschließlich in materialen Inferenzen vor. In semantischer Hinsicht sind jedoch gerade sie besonders informativ. Denn in dem Maße, wie sie schwächer sind als festlegungserhaltende Beziehungen, sind sie auch flexibler und variabler. Insofern ermöglichen sie die Verknüpfung der unterschiedlichsten Überzeugungen, was für das Verständnis von Bedeutung äußerst hilfreich sein kann. Denn es erweitert in entscheidendem Maße das Spektrum dessen, was zur inferentiellen Rolle einer Aussage beiträgt. So lässt sich ihr Ort im logischen Raum der Gründe sehr genau identifizieren. Berechtigungserhaltenden Folgebeziehungen spielen somit bei der Konstitution von Bedeutung eine wichtige Rolle.

Dies verdeutlichen die unterschiedlichen pragmatischen Funktionen festlegungs- und berechtigungserhaltender Inferenzrelationen. Eine Aussage, die inferentiell so gebunden ist, dass sie einen Sprecher auf weitere Aussagen festlegt, steht zu diesen in einer sehr starren Beziehung. Man sagt in einem solchen Fall auch, dass die eine Aussage für die anderen einen zwingenden Grund darstellt. Ist eine Aussage dagegen inferentiell so gebunden, dass sie lediglich eine Berechtigung vererbt, so ist die 
Beziehung weniger starr. Die Konklusion kann inhaltlich stärker von der Prämisse abweichen oder über sie hinausgehen. In diesem Fall redet man eher davon, dass sie für andere Aussagen einen guten Grund darstellt. Die Behauptung etwa, dass die Batterie leer ist, ist ein guter, aber kein zwingender Grund für die Feststellung, dass der Wagen nicht anspringt. Denn man kann sie beispielsweise auch auf die Annahme stützen, dass der Anlasser defekt ist.

Die Beziehung der Unvereinbarkeit schließlich ergibt sich aus den anderen beiden Formen der inferentiellen Beziehung. Sie betrifft Aussagen, zu denen ein Sprecher nicht zugleich berechtigt sein kann. Die Festlegung auf die eine schließt die Berechtigung zur anderen aus. Stehen die Äußerungen oder Zuschreibungen zweier Überzeugungen auf diese Weise in Relation zueinander, dann muss die Festlegung auf einen der beiden aufgegeben werden, soll die Berechtigung zu dem anderen erhalten bleiben. So ist beispielsweise die Behauptung „Kant hat Königsberg zu Lebzeiten nie verlassen.“ mit der Behauptung „Kant reiste regelmäßig nach Lettland." unvereinbar. Wer sich auf ersteres festlegt, ist nicht berechtigt, sich auf letzteres festzulegen. Auch diese dritte Art Inferenzbeziehung trägt zur Konstitution von Bedeutung bei. Die Wortwahl mag irritieren, wird eine Beziehung doch gerade ausgeschlossen. Sie ist aber insofern gerechtfertigt, als Unvereinbarkeitsbeziehungen auf Implikationen und Unterstützungen zurückgehen. Jedenfalls erlaubt auch das, was als mit einer Aussage unvereinbar behandelt wird, Rückschlüsse auf ihre Bedeutung. Es dient als eine Art Kontrastmittel für die Abgrenzung von anderen Aussagen.

Prinzipiell ist es möglich, den Gehalt einer Aussage allein durch die Menge derjenigen Aussagen darzustellen, die mit ihr unvereinbar sind. Zu sagen, dass etwas aus etwas anderem folgt, ist dann gleichbedeutend damit zu sagen, dass mit dem einen all das unvereinbar ist, was auch mit dem anderen unvereinbar ist. Insofern beispielsweise alles, was mit „Berlin liegt östlich von Hamburg.“ unvereinbar ist, auch mit „Hamburg liegt westlich von Berlin." unvereinbar ist, besteht zwischen diesen beiden Aussagen eine festlegungserhaltende Folgebeziehung. Nicht nur direkte Folgebeziehungen, sondern auch indirekte Unvereinbarkeitsbeziehungen sind also bedeutungskonstitutiv. Dadurch lässt sich erahnen, welch reichhaltiges und komplexes Geflecht durch die drei Arten von inferentieller Beziehung 
entsteht. Es wird klar, mit welch großer Trennschärfe sich semantische Gehalte auf diesem Weg unterscheiden lassen.

Mit Hilfe der Unvereinbarkeitsbeziehung lässt sich nun auch die formal-logische Negation als eine explizite Darstellung der sprachlichen Praxis verständlich machen. Diese entspricht nämlich auf formaler Ebene genau dem, was in der Praxis des Behauptens und Zuschreibens von Überzeugungen das Berücksichtigen materialer Unvereinbarkeiten ist. So gesehen lässt sich die Negation einer Aussage als das bezeichnen, was aus all dem folgt, was mit dieser Aussage material unvereinbar ist. ${ }^{269}$ Beispielsweise folgt die Negation der Aussage „Kant war ein Philosoph.“ („Es ist nicht der Fall, dass Kant ein Philosoph war.“) aus den Aussagen „Kant war ein ostpreußischer Forstarbeiter.“, „Kant hat weder ein philosophisches Buch gelesen noch geschrieben.“, „Kant hat sich für ein Verbot der Philosophie eingesetzt." etc. Damit ergibt sich für formallogische Negationen die expressive Funktion, derartige Unvereinbarkeitsbeziehungen sprachlich zu markieren und explizit zu machen. Ausdrücke und Symbole wie „nicht“, „kein“, „, “ oder „, “ sind dann nichts anderes als verkürzte oder formalisierte Darstellungen dieser Art inferentieller Relation.

Wie das Konditional ist aber auch die Negation systematisch gesehen und in Bezug auf das, was im Sprachgebrauch immer schon vor sich geht, nachgeordnet. In der Praxis werden materiale Unvereinbarkeiten längst verhandelt, bevor es zur Einführung eines Ausdrucks kommt, der die inferentielle Rolle der Negation spielt. Wie das Konditional ermöglicht aber auch die Negation einen reflexiven Zugang zu den inferentiellen Gegebenheiten der sprachlichen Praxis. In diesem Fall sind es Unvereinbarkeiten, die explizit Eingang in das Spiel des Gebens und Verlangens von Gründen finden können. Somit schafft auch die Negation die Möglichkeit, das, was wir tun, selbst zum Gegenstand unseres Tuns zu machen. Sie ermöglicht es, Unvereinbarkeitsbeziehungen selbst wieder als Prämisse weiterer Inferenzen zu verwenden. Mit der Negation können wir Unvereinbarkeiten, die wir zuvor lediglich als solche behandelt haben, ausdrücklich als solche bezeichnen und verwenden.

${ }^{269}$ Vgl. ebd., 185 f. u. 541. 
Mit diesem Kapitel ist ein Großteil der angekündigten argumentativen Arbeit geleistet. Es ist deutlich geworden, dass und inwiefern zwei der drei Grundbedingungen für Wissen Können voraussetzen. Denn nicht nur Überzeugungen, sondern auch Rechtfertigungen sind auf die Fähigkeit des „blinden Regelnfolgens“ angewiesen, als welche ich Können ausbuchstabiert habe. Hier sind noch einmal die wichtigsten Punkte des Gedankengangs der letzten beiden Kapitel. Überzeugungen, die sich als Wissen qualifizieren können, sind eine öffentliche Angelegenheit. Sie werden diskursiv und nicht in rein privater Meditation verhandelt. Insofern sind sie immer eine sprachliche und, wie im vierten Kapitel gezeigt, normative Angelegenheit. Für den sprachlichen Umgang mit Überzeugungen ist es erforderlich, die dabei geltenden Regeln befolgen zu können. Hierbei handelt es sich um materiale Inferenzregeln. Charakteristisch für diese Art von Regel ist der Umstand, dass sie nicht als explizite Formulierungen vorliegen, sondern implizit in der diskursiven Praxis vorkommen und befolgt werden. Man kann auch sagen, sie werden „blind“ befolgt. Dennoch handelt es sich um Regeln vom Typ genuin normativer Handlungsnormen. Sie sind verletzbar und erlauben ein Anderskönnen.

Das implizite Befolgen materialer Inferenzregeln ist einerseits die Voraussetzung dafür, dass eine Überzeugung für alle Beteiligten verständlich ist. Überzeugungen haben nur dann eine allgemeingültige und über die Zeit beständige Bedeutung, wenn sie gemäß diesen Regeln verwendet werden. Andererseits ist genau diese Fähigkeit auch die Voraussetzung dafür, eine Überzeugung durch andere Überzeugungen rechtfertigen zu können. Wie ich geltend gemacht habe, ist die Bedeutung einer Aussage ihre inferentielle Rolle. Der bedeutsame Umgang mit Sprache im Allgemeinen und mit Überzeugungen im Besonderen vollzieht sich gemäß geltenden Regeln entlang inferentieller Zusammenhänge. Wer die Bedeutung einer Aussage kennt, versteht es, die entsprechenden Inferenzregeln zu befolgen. Er lokalisiert die Aussage auf die richtige Art und Weise innerhalb des inferentiell gegliederten Diskurses. Insofern heißt, die Bedeutung einer Aussage zu kennen, die entsprechenden inferentiellen Zusammenhänge beherrschen. Dieses Meistern der inferentiellen Gliederung des Sprachspiels der Überzeugung bezeichne ich als Können.

Jemand beherrscht den bedeutungsvollen Gebrauch eines sprachlichen Ausdrucks genau dann, wenn er es versteht, ihn als Grund zu verwenden. 
Schließlich sind inferentielle Zusammenhänge nichts anderes als Begründungszusammenhänge. Und etwas ist nur dann ein Grund für eine Überzeugung, wenn es selbst eine Überzeugung ist. Überzeugungen sind prinzipiell immer Gründe für andere Überzeugungen. Damit ist die inferentielle Gliederung der Sprache einerseits die Voraussetzung für Bedeutung, andererseits für Rechtfertigung. Sie erlaubt das Herstellen von Begründungszusammenhängen, was wiederum dem Problematisieren und Bestätigen von Geltungsansprüchen dient. Wir stützen unsere Behauptungen, indem wir weitere Behauptungen machen, die damit inferentiell zusammenhängen, so wie wir das von anderen Sprechern ebenfalls einfordern. Diese Praxis ist bei der Formulierung von Wissensansprüchen von zentraler Bedeutung. Denn jemand, der etwas zu wissen vorgibt, muss für die entsprechende Überzeugung rechtfertigende Gründe haben. Und diese lassen sich nicht zuletzt deswegen angeben, weil die inferentiellen Zusammenhänge dieser Überzeugung bekannt sind. Auch in dieser Hinsicht bezeichne ich das Meistern der inferentiellen Gliederung des Sprachspiels der Überzeugung als Können.

Damit zeigt sich, dass auf der Ebene der Bedeutungskonstitution prinzipiell dasselbe Können gefordert ist, das auf einer übergeordneten Ebene der Bestätigung von Wissensansprüchen dient. Wissen ist damit in doppelter Hinsicht auf Können angewiesen. Denn etwas ist nur dann Wissen, wenn es eine Überzeugung mit einer Bedeutung ist und wenn es dafür eine Rechtfertigung gibt. Beides ist nur auf der Grundlage des inferentiellen Zusammenhangs möglich, in dem diese Überzeugung steht. Nur wer das Spiel des Gebens und Verlangens von Gründen den geltenden Regeln entsprechend spielen kann, kann bedeutsame Aussagen machen und rechtfertigen. Es muss also Können geben, wo Wissen sein soll. 